\title{
Modeling Windows in Energy Plus with Simple Performance Indices
}

\author{
Dariush Arasteh, Lawrence Berkeley National Laboratory \\ Christian Kohler, Lawrence Berkeley Laboratory \\ Brent Griffith, National Renewable Energy Laboratory
}

October 2009 


\section{DISCLAIMER}

This document was prepared as an account of work sponsored by the United States Government. While this document is believed to contain correct information, neither the United States Government nor any agency thereof, nor The Regents of the University of California, nor any of their employees, makes any warranty, express or implied, or assumes any legal responsibility for the accuracy, completeness, or usefulness of any information, apparatus, product, or process disclosed, or represents that its use would not infringe privately owned rights. Reference herein to any specific commercial product, process, or service by its trade name, trademark, manufacturer, or otherwise, does not necessarily constitute or imply its endorsement, recommendation, or favoring by the United States Government or any agency thereof, or The Regents of the University of California. The views and opinions of authors expressed herein do not necessarily state or reflect those of the United States Government or any agency thereof or The Regents of the University of California. 


\title{
Modeling Windows in Energy Plus with Simple Performance Indices
}

\author{
Dariush Arasteh and Christian Kohler, LBNL \\ Brent Griffith, NREL \\ Contact: D_Arasteh@lbl.gov
}

October 4, 2009

\begin{abstract}
The building energy simulation program, Energy Plus (E+), cannot use standard window performance indices (U, SHGC, VT) to model window energy impacts. Rather, E+ uses more accurate methods which require a physical description of the window. E+ needs to be able to accept $U$ and SHGC indices as window descriptors because, often, these are all that is known about a window and because building codes, standards, and voluntary programs are developed using these terms.
\end{abstract}

This paper outlines a procedure, developed for E+, which will allow it to use standard window performance indices to model window energy impacts. In this "Block" model, a given U, SHGC, VT are mapped to the properties of a fictitious "layer" in E+. For thermal conductance calculations, the "Block" functions as a single solid layer. For solar optical calculations, the model begins by defining a solar transmittance (Ts) at normal incidence based on the SHGC. For properties at non-normal incidence angles, the "Block" takes on the angular properties of multiple glazing layers; the number and type of layers defined by the U and SHGC.

While this procedure is specific to E+, parts of it may have applicability to other window/building simulation programs.

\section{Problem/ Background}

The building energy simulation program, Energy Plus (E+), cannot use simple window indices (U-factor, Solar Heat Gain Coefficient, and Visible Transmittance) to model the energy impacts of windows, as can be done in DOE2 and many other such programs. E+ typically uses a layer by layer window description (i.e. two layers of clear glass, separated by a $12 \mathrm{~mm}$ air space, with an aluminum frame) or it can use a more detailed output file from the WINDOW5 or WINDOW6 software program. The algorithms used by E+ to model window thermal and optical effects are similar to those in WINDOW5, 
but the process of doing these detailed calculations every time-step can be very time consuming. E+ needs to be able to accept $\mathrm{U}$ and SHGC indices as window descriptors because of several important reasons:

- Sometimes, the only thing that is known about the window are its U and SHGC;

- Codes, standards, and voluntary programs are developed in these terms;

- Speed of calculation is sometimes an issue.

[Note: This use of U and SHGC to describe the thermal properties of windows is only appropriate for specular glazings.]

[Note: Although standardized values for SHGC are determined for normal incidence, this is actually a very rare occurrence during energy simulations where the vast majority of the time the windows experience relatively high incidence angles. This procedure addresses the topic of converting normal incidence SHGC to angular dependent data.]

While it is important to include the ability to model windows with only $\mathrm{U}$ and SHGC, any method to use U and SHGC alone in building simulation software will inherently be approximate. This is due primarily to the following factors:

- SHGC combines directly transmitted solar radiation and radiation absorbed by the glass which flows inward. These have different implications for space heating/cooling. Different windows with the same SHGC often have different ratios of transmitted to absorbed solar radiation.

- SHGC is determined at normal incidence; angular properties of glazings vary with number of layers, tints, coatings. So products which have the same SHGC, can have different angular properties. See Figure 1.

- Window U-factors vary with temperatures.

Thus, for modeling specific windows, we recommend using more detailed data than just the $\mathrm{U}$ and SHGC, if at all possible. The procedure outlined in this paper contains several approximations; however these approximations are inherent in the assumption that $\mathrm{U}$ and SHGC alone can describe the thermal performance of windows. 


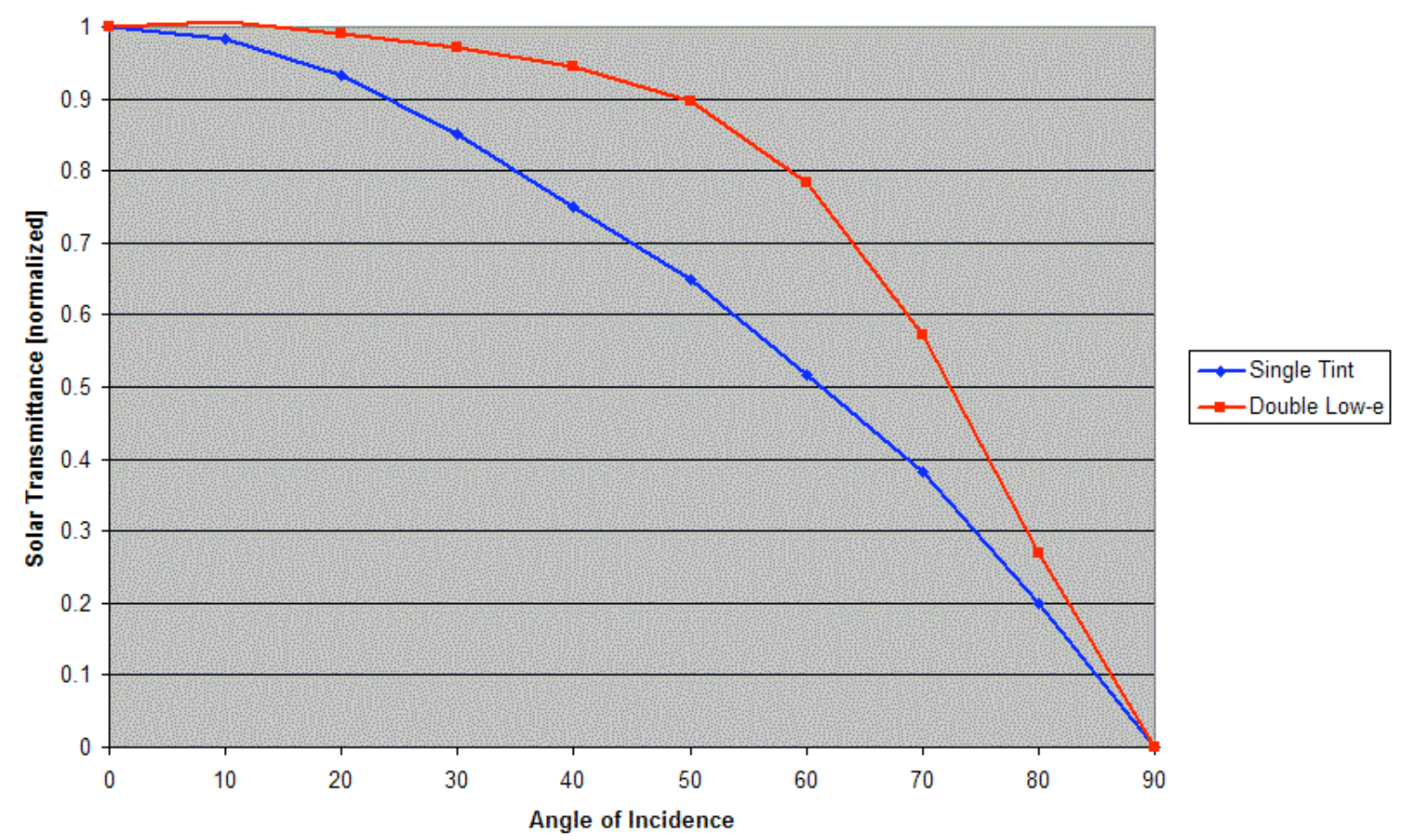

Figure 1 - The angular dependence for two glazing systems, both with SHGC=0.35 but with very different angular responses, is shown. In addition, the tinted glazing has a Ts (solar transmittance) of .06 while the low-e glazing has a Ts of 0.34; showing widely different ratios of transmitted to absorbed solar radiation. [Note: typically, differences are not as great.]

Currently, when asked to model a given U/SHGC combination in E+; spectral data files or single layer properties are found or created which result in a window with the necessary U/SHGC. This procedure, even if refined, has several intrinsic problems:

- It is cumbersome: $100 \mathrm{U}$ and 100 SHGC options is 10,000 files or layers;

- If VT is an issue, then $100 * 10,000$ cases are required;

- It is still a long calculation time, for an approximate result.

Most importantly, whatever process is defined, needs to be a "continuous process" not a "stepped process" so that small changes in U or SHGC produce corresponding small energy changes; there cannot be a "jump" where at a given U or SHGC, the "window" modeled changes from single to double glazing, from coated to tinted glazings. For example, if real products were chosen to represent specific U and SHGC values, a product with a SHGC of .41 may be a tinted product, an SHGC of .40 may also be a tinted product, but SHGCs of .39 and .38 may end up being reflective products. [Tinted and reflective products have different angular correlations and different ratios of transmitted to absorbed solar radiation, both of which impact window energy use, even if $\mathrm{U}$ and SHGC are constant.] The window energy use difference between 0.41 and 0.40 (one tinted product to another) may be very different than the difference from 40 to .39 (one tinted to one reflective) or from 0.39 to 0.38 (one reflective to another). The process presented here is generic and intended to smooth out any jumps between product classes. 


\section{Outline of Procedure}

The procedure presented in this paper for using $\mathrm{U}$ and SHGC in E+ revolves around the development of a simple "Block Model" concept where a given U, SHGC, VT are mapped to the properties of a fictitious "layer" in E+. For thermal conductance calculations, the "Block" functions as a single layer. Such a layer will have the necessary effective conductivity (Keff) to properly represent the $\mathrm{U}$ factor given; for example, it may have a very low effective conductivity to simulate highly insulating windows. For solar optical calculations, the model begins by defining a solar transmittance (Ts) at normal incidence based on the SHGC (this is developed by an analysis of current product data). For properties at non-normal incidence angles, the "Block" takes on the angular properties of multiple glazing layers; the number of layers deduced by the U and SHGC. Using this model, E+ can then obtain heat fluxes and window surface temperatures, as needed for other space calculations. Figure 2 explains this Block model graphically. Specifics are outlined in detail in the next section.
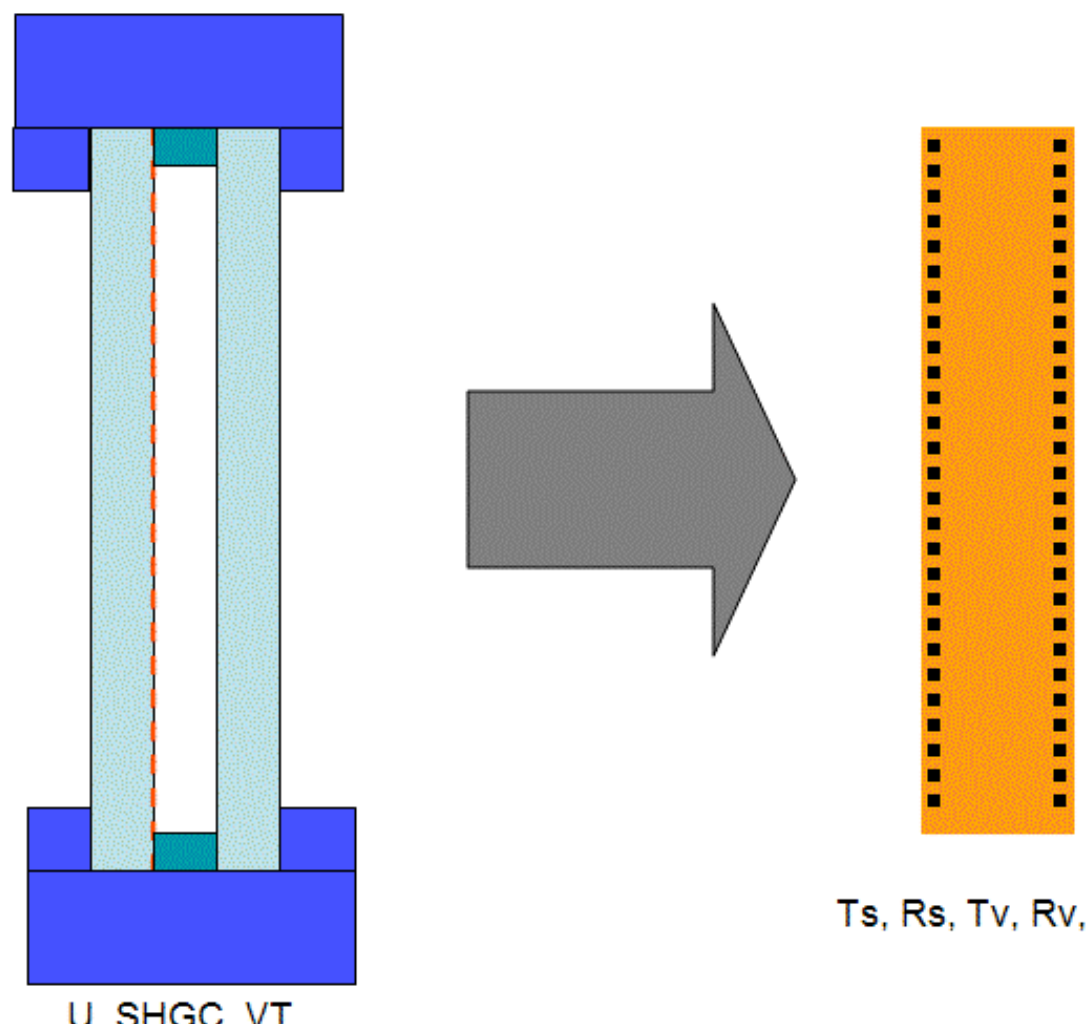

Ts, Rs, Tv, Rv, Keff

Figure 2 - Simplification of whole window properties into simple layer properties 
It is easy to point out that the procedure presented here is not as accurate as more detailed models of a window system which are embedded in E+ or other building simulation program. It should be pointed out that this procedure is more representative of reality than the old U/SHGC model in DOE2. This procedure is not proposed in lieu of more detailed models, but is proposed for use when U and SHGC are the only available metrics.

As shown in the following steps and their accompanying graphs, this procedure was based on an analysis of numerous commercially available products, combined with underlying window heat transfer analysis. In some steps, this requires making the assumption that film coefficients along the frame are the same as those along the glazing - an assumption often made in simplified window heat transfer. The window products chosen for this analysis were frameless products (glazing systems with only center-ofglass properties). We maintain that the relationships developed here for frameless windows hold true (in the context of simplified modeling) for the modeling of window properties in $\mathrm{E}+$, no matter what the window is comprised of. With this simplified method, a full window with frame, etc. and a glazing only window, both with the same $\mathrm{U} / \mathrm{SHGC} / \mathrm{VT}$, must have the same annual energy results from $\mathrm{E}+$ because their inputs are the same. A more detailed analysis, using more than just U/SHGC/VT would probably show differences in the windows' annual energy and peak use. (Appendix 1 to Step 4 shows how the presence or lack of frames does not influence the correlations developed in this study.)

\section{Technical Procedure}

The technical procedure outlined here builds on work by many individuals to characterize window heat transfer. For background material on this process, we reference ISO 2003 and Finlayson 1993.

We start with simple input properties for a window (U, SHGC, and sometimes VT) and need to translate these into the following properties for a "Representative Layer," so that when used in $\mathrm{E}+$, these glazing layer properties result in a window system with the original U, SHGC, and VT at NFRC conditions. Once the representative layer is defined, the formal calculations in ISO Standard 15099 (2003) and Finlayson 1993 are applied to model the layer, except for off-normal solar incidence angles which use new methods discussed later in this procedure.

[Our convention is that window U-factors include the interior and exterior film coefficients; R-values do not.]

All units are in SI, unless otherwise noted.

Keff $=$ effective conductivity of the glazing system $(\mathrm{W} / \mathrm{m}-\mathrm{K})$

$\mathrm{d}=$ thickness of the glazing system $(\mathrm{mm})$

Ts - Solar transmittance of the glazing system, at normal incidence 
Rs-f, front side solar reflectance, at normal incidence

Rs-b, back side solar reflectance, at normal incidence

$\mathrm{Tv}$ - visible reflectance, at normal incidence

$\mathrm{Rv}-\mathrm{f}$, front side visible reflectance, at normal incidence

$\mathrm{Rv}$-b, back side visible reflectance, at normal incidence

Tir - long wave hemispherical infrared transmittance, defined as 0 for this procedure $\mathrm{Ef}$ and $\mathrm{Eb}$ - front and back side hemispherical emittances, assumed to be 0.84 (noncoated) for this procedure

The general procedure presented here is valid for windows at any tilt (skylights, sloped glazing, as well as conventional vertical windows.) For non-vertical windows however, Steps 1 and 5 which use interior film coefficients (which are a function of tilt) will need to be modified. This is not covered in this paper.

\section{Step 1: Determine glass-to-glass Resistance}

E+ calculates interior and exterior film coefficients every time step, depending on environmental conditions. It adds these film coefficients to a resistance for the solid window product, or glass-to-glass resistance. In other words:

$$
1 / \mathrm{U}=\mathrm{Ri}-\mathrm{w}+\mathrm{Ro}-\mathrm{w}+\mathrm{Rl}-\mathrm{w}
$$

Where

$\mathrm{Ri}-\mathrm{w}=$ resistance of interior film coefficient $(\mathrm{m} 2-\mathrm{K} / \mathrm{W})$ under winter conditions Ro- $\mathrm{w}=$ resistance of outside film coefficient $(\mathrm{m} 2-\mathrm{K} / \mathrm{W})$ under winter conditions $\mathrm{Rl}-\mathrm{w}=$ resistance of "Representative Layer" $(\mathrm{m} 2-\mathrm{K} / \mathrm{W})$ under winter conditions (also referred to as the glass-to-glass resistance)

Ri-w is function of U-factor and could either be determined analytically in an iterative fashion, or could be extremely well approximated from Figure 3 which gives Ri-w as a function of U-factor for vertical windows.

Ro-w is effectively a constant, although as also shown in Figure 3, is a slight function of U-factor. It does not change for windows installed at tilts other than vertical.

We can thus solve for Rl-w. It is reasonable to state that $\mathrm{Rl}-\mathrm{w}$ is representative of $\mathrm{Rl}$ for all other environmental conditions. 
Film Coefficient as function of U-value

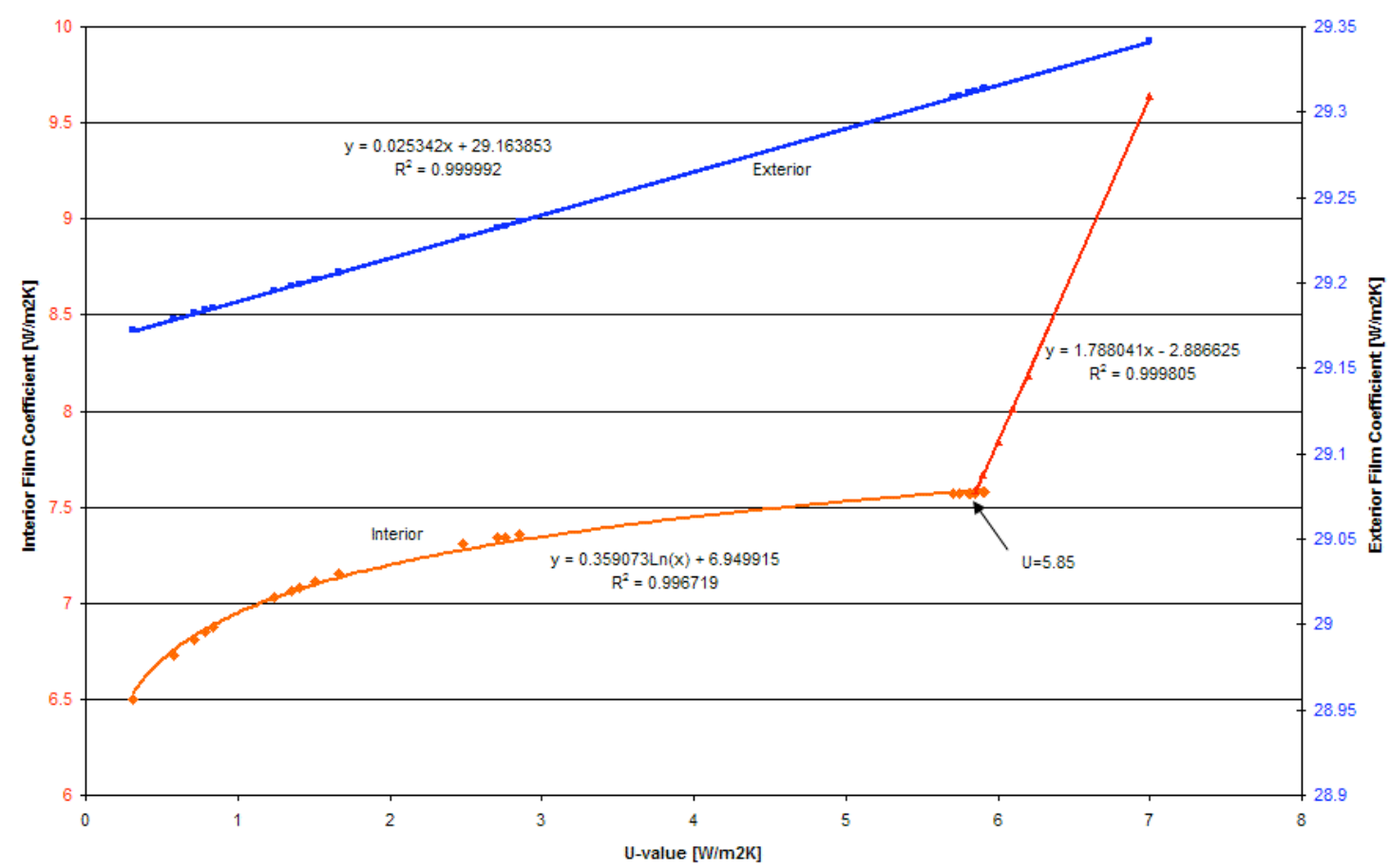

Figure 3 - Film coefficient as a function of U-value. Interior film coefficient on the left (red) scale, and exterior film coefficient on the right (blue) scale.

For $\mathrm{U}<5.85: \quad \mathrm{Ri}-\mathrm{w}=1 /(0.359073 \operatorname{Ln}(\mathrm{U})+6.949915)$

For $\mathrm{U} \geq 5.85: \quad \mathrm{Ri}-\mathrm{W}=1 /(1.788041 * \mathrm{U}-2.886625)$

$\mathrm{Ro}-\mathrm{w}=1 /(0.025342 * \mathrm{U}+29.163853)$

Figure 3 shows that the interior film coefficient curve consists of two sections. This is needed because at $\mathrm{U}>5.85 \mathrm{~W} / \mathrm{m} 2 \mathrm{~K}, \mathrm{Ri}-\mathrm{w}$ (based on curved fit) + Ro-w is greater than $1 / \mathrm{U}$, which would result in a negative value for Rl-w. The linear section for $\mathrm{U}>5.85$ $\mathrm{W} / \mathrm{m} 2 \mathrm{~K}$ represent single glazed windows with highly conductive and projecting frames.

\section{Step 2: Determine Thickness}

The thickness, $\mathrm{d}$, is arbitrary. We let $\mathrm{d}$ vary with $\mathrm{U}$-factor as this is typical of real products. A window with a surface-to-surface, or bare, U-factor of $7 \mathrm{~W} / \mathrm{m} 2-\mathrm{K}$ or greater might have a thickness of $2 \mathrm{~mm}$ and one with a bare $\mathrm{U}$-factor of $1 \mathrm{~W} / \mathrm{m} 2-\mathrm{K}$ may have a thickness of $52 \mathrm{~mm}$. We fit a line through these 2 points and are given:

For 1/ Rl-w > 7, d = 2

Else, $d=59.14-7.14 / \mathrm{Rl}-\mathrm{w}$

Where $\mathrm{d}$ has units of millimeters. 


\section{Step 3: Determine Thermal Conductivity}

The effective thermal conductivity of the "Representative Layer" (W/m-K) is derived from the glass-to-glass resistance:

Keff $=\mathrm{d} / \mathrm{Rl}-\mathrm{w}$.

\section{Step 4: Determine Ts.}

We start with the given that:

$\mathrm{SHGC}=\mathrm{Ts}+\mathrm{NA}$

Where

Ts is the solar transmittance

$\mathrm{N}$ is the inward flowing fraction for the Representative Layer and

A is the absorptance of the Representative Layer

We have plotted (center of glass) Ts vs (center-of-glass) SHGC for hundreds of glazing systems determined using glazing data from the LBNL International Glazing DataBase (IGDB at windows.lbl.gov/software). This data is plotted in Figures $4 \mathrm{a}$ and $4 \mathrm{~b}$ and allows us to determine a reasonable Ts for a given SHGC. [Note: While the data available is for center-of-glass properties, the same relationship holds true for whole window properties.] Details are presented in Appendix 1. 


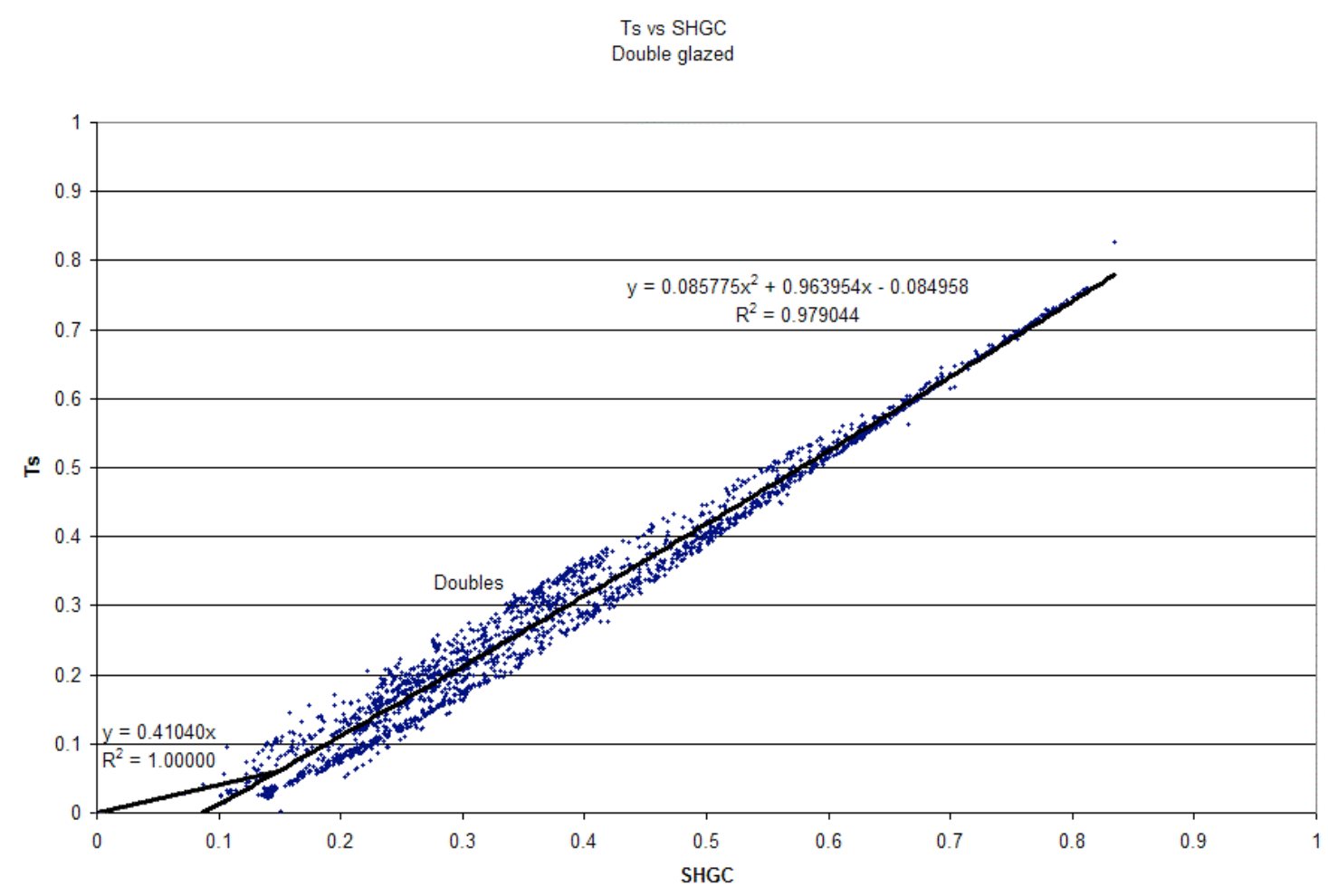

Figure $4 a$ - Variation of SHGC vs Ts based on double glazing systems

Ts vs SHGC

Single reflective and tinted

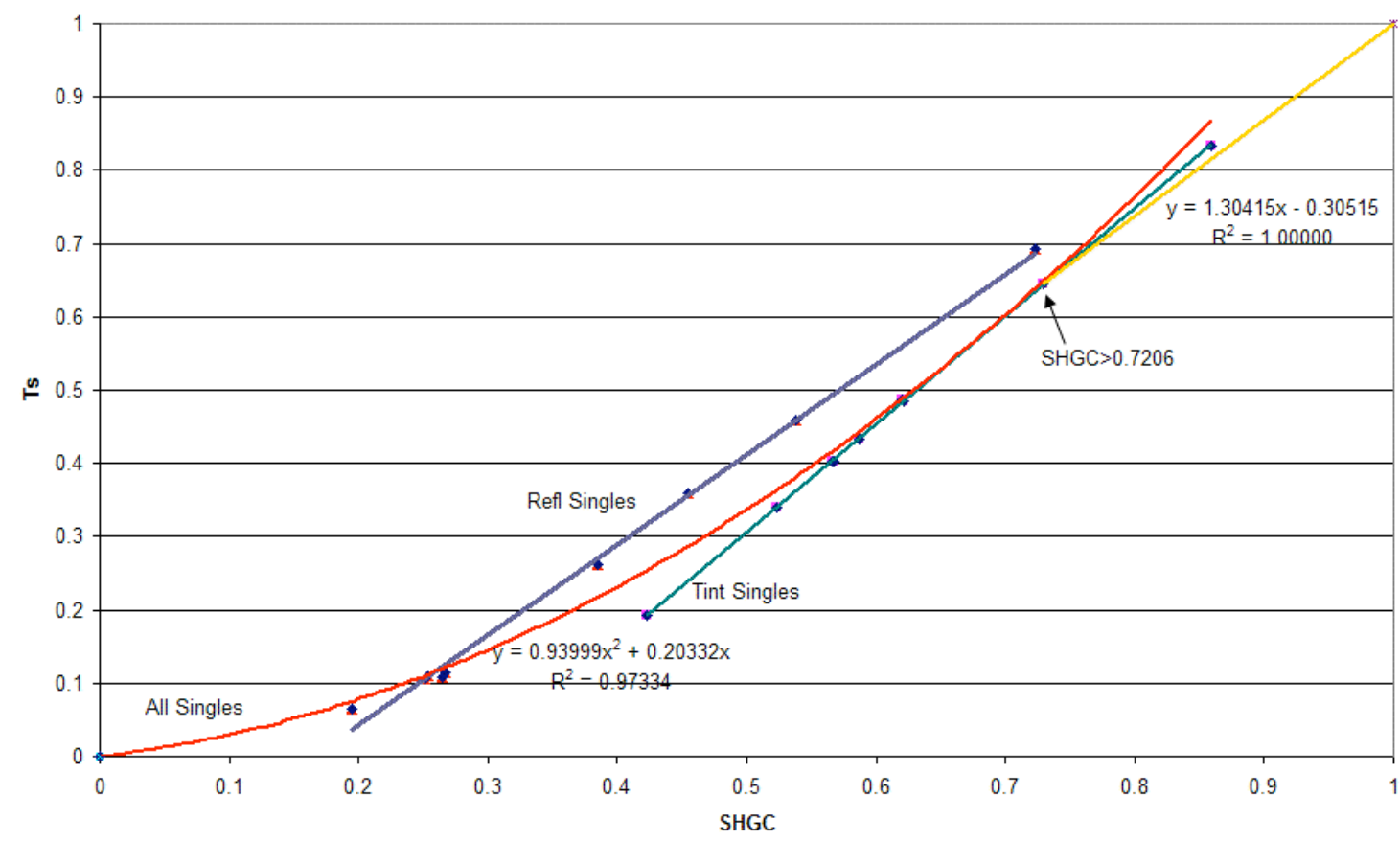

Figure $4 b-$ Variation of SHGC vs Ts based single glazed systems 
The relationship between Ts and SHGC is different for single and double glazing. We therefore use:

For $\mathrm{U}>4.5 \mathrm{~W} / \mathrm{m} 2 \mathrm{~K}$ (single glazed):

For SHGC $<0.7206$ Ts $=\left(0.939998 * \mathrm{SHGC}^{\wedge} 2\right)+(0.20332 *$ SHGC $)$

For $\mathrm{SHGC} \geq 0.7206$

$\mathrm{Ts}=(1.30415 * \mathrm{SHGC})-0.30515$

For $\mathrm{U}<3.4 \mathrm{~W} / \mathrm{m} 2 \mathrm{~K}$ (double glazed or better):

For $\mathrm{SHGC} \leq 0.15$, Ts $=0.41040 *$ SHGC

For $\mathrm{SHGC}>0.15$, $\mathrm{Ts}=\left(0.085775 * \mathrm{SHGC}^{\wedge} 2\right)+(0.963954 * \mathrm{SHGC})-0.084958$

For $3.4 \leq$ Uwindow $\leq 4.5$

Interpolate between the results for single and the result for double glazing.

\section{Step 5: Determine Rs and Rb}

We take as given that:

Ts+ Rs-f + As $=1.0$.

Given we know Ts and we know something about As (As=SHGC/N), all we need to know is N. [We are primarily interested in Rs-f as this is the reflectance relevant to heat transfer calculations.]

SHGCs are determined under NFRC Summer conditions (as opposed to U-factors which are determined in the absence of sunlight.)

Assuming the solar radiation absorbed is absorbed in the center of the "Representative Layer," then

$\mathrm{N}=($ Ro-s+ 0.5*Rl) / (Ro-s + Rl + Ri-s)

Where:

$\mathrm{Ri}-\mathrm{s}=$ resistance from the interior film coefficient under NFRC (ASHRAE) Summer Conditions

Ro-s $=$ resistance from the outside film coefficient under NFRC (ASHRAE) Summer Conditions

$\mathrm{Rl}=$ resistance of the "Representative Layer," assumed to be the same in the summer as in the winter 
To determine Ri-s and Ro-s, we looked at numerous typical single and double glazed products. Film coefficients for single and double glazed products are examined separately, and a curve is fitted to this data. This is shown in Figure 5 (interior) and Figure 6 (exterior). [Triple and other multiple glazed units are not expected to perform much differently than doubles glazed units.] Since the Resistance is the inverse of the film coefficient, we end up with the following correlations, where U-factor is used to define singe or double glazed products.

\section{Summer Interior Film Coefficient}

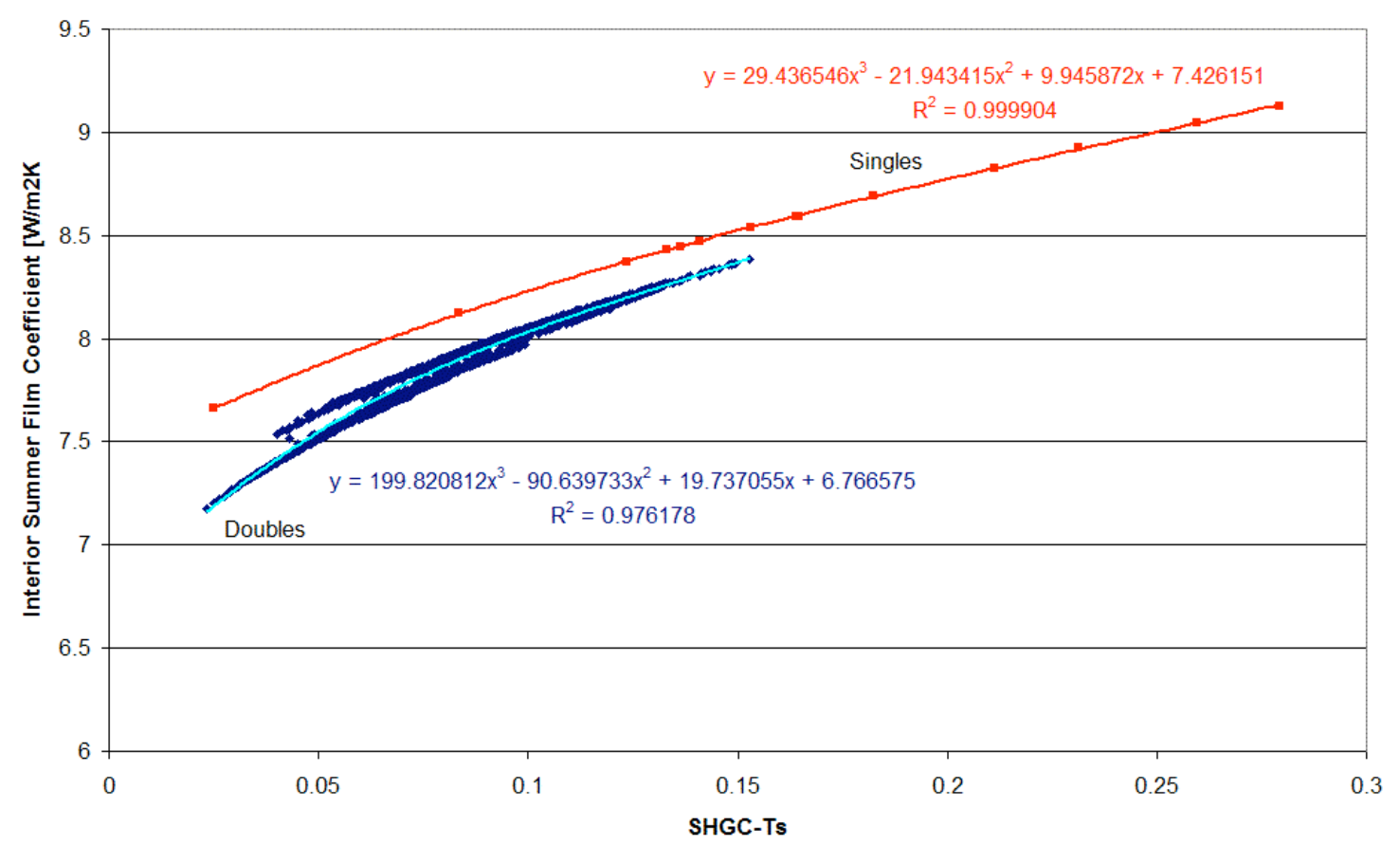

Figures 5 - Summer interior film coefficients for numerous single and double glazed products. 
Exterior summer film coefficient

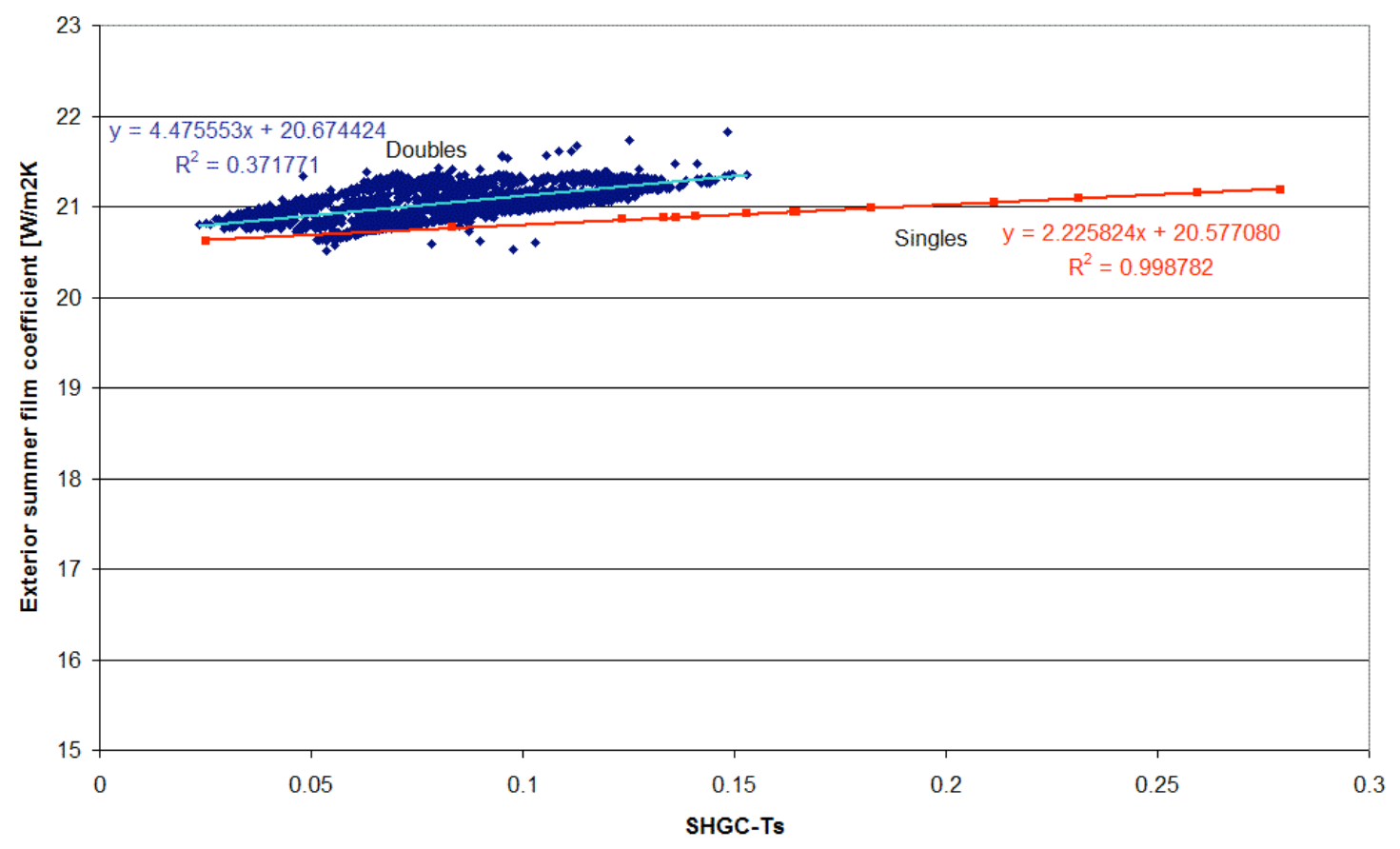

Figure 6 - Summer exterior film coefficients for numerous single and double glazed products.

For $\mathrm{U}>4.5 \mathrm{~W} / \mathrm{m} 2 \mathrm{~K}$ ( single glazed):

$\mathrm{Ri}-\mathrm{s}=1 /\left(\left(29.436546^{*} \mathrm{x}^{\wedge} 3\right)-\left(21.943415^{*} \mathrm{x}^{\wedge} 2\right)+(9.945872 * \mathrm{x})+7.426151\right)$

Ro-s $=1 /((2.225824 * \mathrm{x})+20.577080)$

Where $\mathrm{x}=$ SHGC-Ts

For $\mathrm{U}<3.4 \mathrm{~W} / \mathrm{m} 2 \mathrm{~K}$ (double glazed):

$\mathrm{Ri}-\mathrm{s}=1 /\left(\left(199.8208128 * \mathrm{x}^{\wedge} 3\right)-\left(90.639733 * \mathrm{x}^{\wedge} 2\right)+\left(19.737055^{*} \mathrm{x}\right)+6.766575\right)$

Ro-s $=1 /((4.475553 * \mathrm{x})+20.674424)$

Where $\mathrm{x}=$ SHGC-Ts

For $3.4 \leq \mathrm{U} \leq 4.5$

Interpolate between the results for single and the result for double glazing.

Once $\mathrm{N}$ is determined, then

$\mathrm{As}=(\mathrm{SHGC}-\mathrm{Ts}) / \mathrm{N}$

And Rs-f = 1-Ts-As 
For glazings with solar control coatings, Rs-b will be different from Rs-f. For clear and tinted glazings, it will be identical. As it is a required field, we need to define it. For simplicity, we let

Rs-b=Rs-f.

\section{Step 6: Determine Visible Properties}

If a VT is given for the window system, this is assumed to be the Tv for the Representative Layer. The visible reflectances for the Representative Glazing Layer are assumed to be representative of typical products, and are taken from Figure 7.

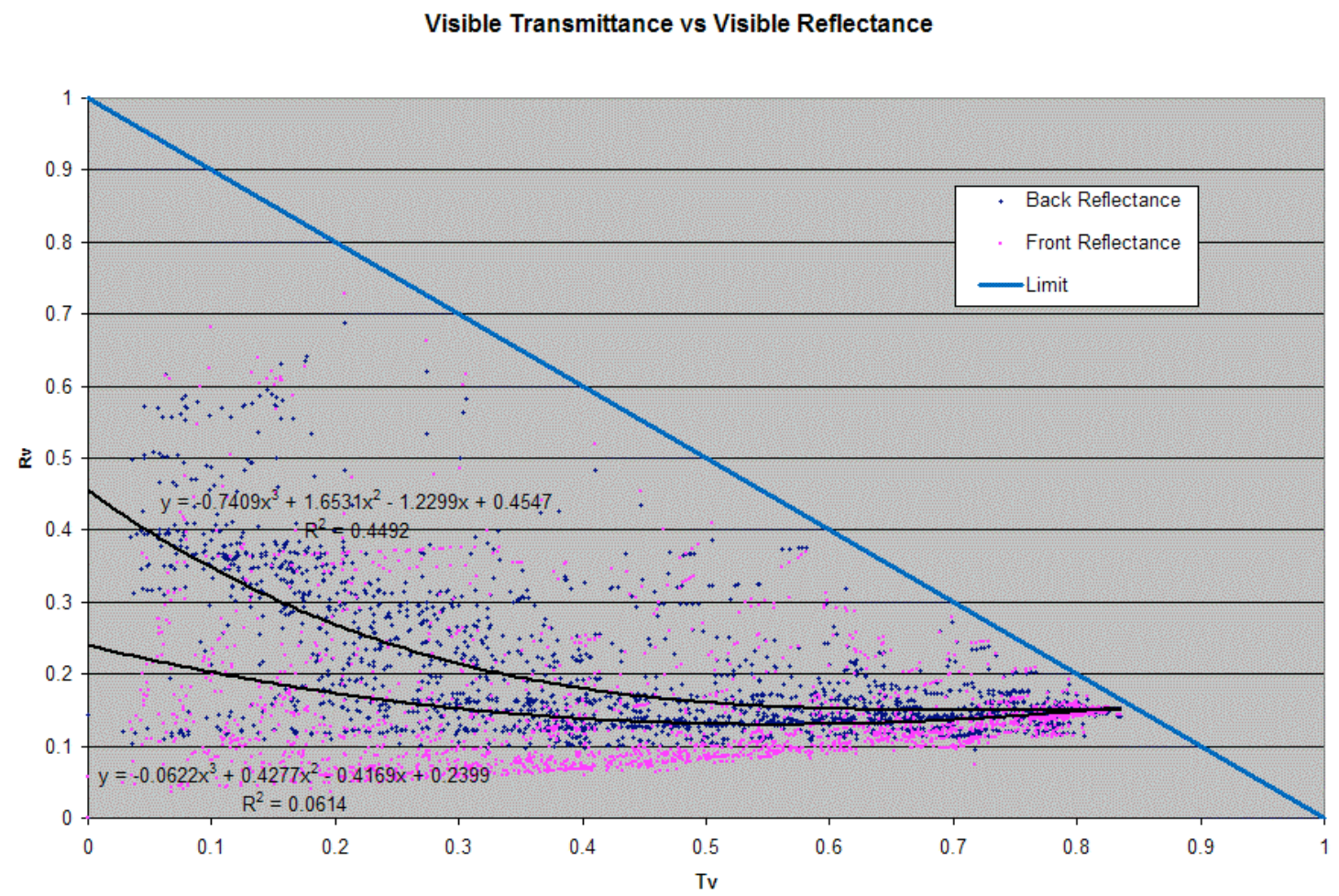

Figure 7 - Relationship between VT and front and back visible reflectance.

If there is no VT given the visible properties for the Representative Layer are assumed to be the same as the solar properties. Otherwise:

$\mathrm{TV}=\mathrm{VT}$

$\mathrm{Rv}-\mathrm{f}=-0.0622 * \mathrm{Tv}^{\wedge} 3+0.4277 * \mathrm{Tv}^{\wedge} 2-0.4169 * \mathrm{Tv}+0.2399$

$\mathrm{Rv}-\mathrm{b}=-0.7409 * \mathrm{Tv}^{\wedge} 3+1.6531 * \mathrm{Tv}^{\wedge} 2-1.2299 * \mathrm{Tv}+0.4545$ 


\section{Step 7: Determine Angular Properties for Solar and Visible}

In general, angular properties of a glazing system vary mostly with angle of incidence, and then with number of layers and type of glazing. The method developed for this procedure uses the U and SHGC to determine the most probable composition of the window: whether the window is single, double, or triple glazed and what type of glazing it uses. From this information, normalized transmission and reflectance are determined as a function of incidence angle. We define nine possible sub-groups a window system could fall into depending on its U/SHGC with each subgroup having appropriate normalized angular transmission and reflectance curves. We define a normalized transmittance factor as $\mathrm{Ts}($ angle $) / \mathrm{Ts}(0)$ and a normalized reflectance factor as $\mathrm{Rs}($ angle)/Rs(0). The table below illustrates these nine "boxes;" note that these are not contiguous boxes; properties for windows in-between are interpolated in order to ensure smooth transitions in angular properties with small U or SHGC changes. The correlations, or Angular Curves, used are given below the table. A broader discussion of how this procedure was developed is given in Appendix 2. We begin by defining ten angular curves for common glazing:
A- $3 m m$ clear
B- $3 \mathrm{~mm}$ bronze
C- $6 \mathrm{~mm}$ bronze
D-Single Coated
E-Double clear $3 \mathrm{~mm}$
F-Double coated $3 \mathrm{~mm}$ clear
G-Double $3 \mathrm{~mm}$ tinted $3 \mathrm{~mm}$ clear
H-Double glazing: coated - $6 \mathrm{~mm}$ clear
I-Double Glazing: $6 \mathrm{~mm}$ tinted - $6 \mathrm{~mm}$ clear
J-Triple-Coated-3mm clear-coated

Next, we define define the nine possible sub-groups a window system could fall into depending on its U/SHGC:

\begin{tabular}{|c|c|c|c|}
\hline Total Window Properties & High U (U>4.5) & $\begin{array}{l}\text { Mid-U } \\
(1.7<U<3.4)\end{array}$ & $\begin{array}{l}\text { Low- U } \\
(\mathrm{U}<1.4)\end{array}$ \\
\hline $\begin{array}{l}\text { SHGC>.65 for High } U ; \\
\text { SHGC> } .55 \text { for Mid U; } \\
\text { SHGC>.45 for Low U; }\end{array}$ & $\begin{array}{l}\text { Angular Curve A. } \\
\text { (represents single } \\
\text { glazing) }\end{array}$ & $\begin{array}{l}\text { Angular Curve E. } \\
\text { (represents } \\
\text { double and some } \\
\text { low-e double) }\end{array}$ & $\begin{array}{l}\text { Angular } \\
\text { Curve E. } \\
\text { (represents } \\
\text { double low-e) }\end{array}$ \\
\hline $\begin{array}{l}.6<\text { SHGC }<.45 \text { for High } \mathrm{U} \\
.5<\mathrm{SHGC}<.3 \text { For Mid U }\end{array}$ & $\begin{array}{l}\text { Weighted } \\
\text { Average of } \\
\text { angular curves B }\end{array}$ & $\begin{array}{l}\text { Average of } \\
\text { angular curves F, } \\
\mathrm{G}, \mathrm{H} \text {, and I (a.k.a. }\end{array}$ & $\begin{array}{l}\text { Angular } \\
\text { Curve J. } \\
\text { (represents }\end{array}$ \\
\hline
\end{tabular}




\begin{tabular}{|c|c|c|c|}
\hline $.35<$ SHGC<.18 For Low U & $\begin{array}{l}(25 \%), \mathrm{C}(25 \%), \\
\text { and D }(50 \%) . \\
\text { (a.k.a. Angular } \\
\text { curve "BDCD). } \\
\text { (represents an } \\
\text { average of } \\
\text { various tinted and } \\
\text { reflective single } \\
\text { glazings) }\end{array}$ & $\begin{array}{l}\text { (Angular Curve } \\
\text { "FGHI"). } \\
\text { (represents an } \\
\text { average of } \\
\text { various tinted, } \\
\text { low-e, and } \\
\text { reflective double } \\
\text { glazings) }\end{array}$ & $\begin{array}{l}\text { triple glazed } \\
\text { products with } \\
\text { two low-e } \\
\text { layers) }\end{array}$ \\
\hline $\begin{array}{l}\text { SHGC }<.3 \text { for High } U \\
\text { SHGC }<.25 \text { for Mid } U \\
\text { SHGC }<.15 \text { for Low } U\end{array}$ & $\begin{array}{l}\text { Angular Curve D. } \\
\text { (represents single } \\
\text { reflective glazing) }\end{array}$ & $\begin{array}{l}\text { Average of } \\
\text { angular curves F } \\
\text { and H (a.k.a. } \\
\text { Angular Curve } \\
\text { "FH"). } \\
\text { (represents } \\
\text { double glazing } \\
\text { with low-e or } \\
\text { reflective) }\end{array}$ & $\begin{array}{l}\text { Angular } \\
\text { Curve J. } \\
\text { (represents } \\
\text { triple glazed } \\
\text { products with } \\
\text { two low-e } \\
\text { layers) }\end{array}$ \\
\hline
\end{tabular}

The curves presented below are normalization factors applied to the transmittance and reflectance at normal ( 0 degrees) incidence. Thus, for transmittance, the normalization factor is 1.0 at normal incidence and 0 at 90 degrees. For reflectance, the normalization factor is 1.0 at normal incidence (where reflectance is between .05 and .1 typically), increasing to something on the order of 10-20 at 90 degrees (where the reflectance is 1.0). As noted in the beginning, all the angular correlations presented here were developed based on generic product solar transmission and reflection data. We use these same correlations for the angular correlations for visible transmittance and reflectance due to the fact that they are inherently similar. When implementing these correlations, we propose that:

- the normalized transmittances be forced to 1.0 and 0 at 0 degrees and 90 degrees respectively;

- the normalized reflectance be forced to 1.0 at 0 degrees and the absolute reflectance be forced to 1.0 at 90 degrees;

- these curves be used to generate data between 10 and 80 degrees; with linear interpolation between 0 and 10 degrees, and then between 80 and 90 degrees. 
$\mathrm{Z}=\cos ($ angle $)$

T or $R=a^{\star} Z^{\wedge} 4+b^{\star} Z^{\wedge} 3+c^{\star} Z^{\wedge} 2+d^{\star} Z+e$

\begin{tabular}{|l|r|r|r|l|l|}
\hline & \multicolumn{5}{|c|}{ Normalized Transmittance } \\
\hline & $\mathrm{a}$ & $\mathrm{b}$ & $\mathrm{c}$ & $\mathrm{d}$ & $\mathrm{e}$ \\
\hline $\mathrm{A}-3 \mathrm{~mm}$ clear & $1.470 \mathrm{E}-02$ & $1.486 \mathrm{E}+00$ & $3.852 \mathrm{E}+00$ & $-3.355 \mathrm{E}+00$ & $-1.474 \mathrm{E}-03$ \\
\hline B- 3mm bronze & $5.546 \mathrm{E}-01$ & $3.563 \mathrm{E}-02$ & $2.416 \mathrm{E}+00$ & $2.831 \mathrm{E}+00$ & $-2.037 \mathrm{E}-03$ \\
\hline C- 6mm bronze & $7.709 \mathrm{E}-01$ & $-6.383 \mathrm{E}-01$ & $1.576 \mathrm{E}+00$ & $2.448 \mathrm{E}+00$ & $-2.042 \mathrm{E}-03$ \\
\hline $\begin{array}{l}\text { D-Single Coated } \\
\text { E-Double clear 3mm }\end{array}$ & $3.462 \mathrm{E}-01$ & $3.963 \mathrm{E}-01$ & $2.582 \mathrm{E}+00$ & $2.845 \mathrm{E}+00$ & $-2.804 \mathrm{E}-04$ \\
\hline $\begin{array}{l}\text { F-Double coated 3mm clear } \\
\text { G-Double 3mm tinted 3 mm } \\
\text { clear }\end{array}$ & $2.883 \mathrm{E}+00$ & $-5.873 \mathrm{E}+00$ & $2.489 \mathrm{E}+00$ & $1.510 \mathrm{E}+00$ & $-2.577 \mathrm{E}-03$ \\
\hline $\begin{array}{l}\text { H-Double glazing: coated - } \\
\text { 6mm clear }\end{array}$ & $3.025 \mathrm{E}+00$ & $-6.366 \mathrm{E}+00$ & $3.137 \mathrm{E}+00$ & $1.213 \mathrm{E}+00$ & $-1.367 \mathrm{E}-03$ \\
\hline $\begin{array}{l}\text { I-Double Glazing:6mm tinted - } \\
\text { 6mm clear }\end{array}$ & $3.229 \mathrm{E}+00$ & $-6.844 \mathrm{E}+00$ & $3.535 \mathrm{E}+00$ & $1.088 \mathrm{E}+00$ & $-2.891 \mathrm{E}-03$ \\
\hline $\begin{array}{l}\text { J-Triple-Coated-3mm clear- } \\
\text { coated }\end{array}$ & $3.146 \mathrm{E}+00$ & $-6.855 \mathrm{E}+00$ & $3.931 \mathrm{E}+00$ & $7.860 \mathrm{E}-01$ & $-2.934 \mathrm{E}-03$ \\
\hline
\end{tabular}

\begin{tabular}{|l|l|l|l|l|l|}
\hline & \multicolumn{5}{|c|}{ Normalized Reflectance } \\
\hline & $\mathrm{a}$ & $\mathrm{b}$ & $\mathrm{c}$ & $\mathrm{d}$ & $\mathrm{e}$ \\
\hline $\mathrm{A}-3 \mathrm{~mm}$ clear & $1.632 \mathrm{E}+01$ & $-5.782 \mathrm{E}+01$ & $7.924 \mathrm{E}+01$ & $-5.008 \mathrm{E}+01$ & $1.334 \mathrm{E}+01$ \\
\hline B- 3mm bronze & $4.048 \mathrm{E}+01$ & $-1.193 \mathrm{E}+02$ & $1.348 \mathrm{E}+02$ & $-7.097 \mathrm{E}+01$ & $1.611 \mathrm{E}+01$ \\
\hline C- 6mm bronze & $5.749 \mathrm{E}+01$ & $-1.645 \mathrm{E}+02$ & $1.780 \mathrm{E}+02$ & $-8.875 \mathrm{E}+01$ & $1.884 \mathrm{E}+01$ \\
\hline D-Single Coated & $5.714 \mathrm{E}+00$ & $-1.667 \mathrm{E}+01$ & $1.863 \mathrm{E}+01$ & $-9.756 \mathrm{E}+00$ & $3.074 \mathrm{E}+00$ \\
\hline E-Double clear 3mm & $-5.488 \mathrm{E}-01$ & $-6.498 \mathrm{E}+00$ & $2.120 \mathrm{E}+01$ & $-2.097 \mathrm{E}+01$ & $7.814 \mathrm{E}+00$ \\
\hline F-Double coated 3mm clear & $4.290 \mathrm{E}+00$ & $-1.267 \mathrm{E}+01$ & $1.466 \mathrm{E}+01$ & $-8.153 \mathrm{E}+00$ & $2.871 \mathrm{E}+00$ \\
\hline $\begin{array}{l}\text { G-Double 3mm tinted 3 mm } \\
\text { clear }\end{array}$ & $2.174 \mathrm{E}+01$ & $-6.444 \mathrm{E}+01$ & $7.489 \mathrm{E}+01$ & $-4.179 \mathrm{E}+01$ & $1.062 \mathrm{E}+01$ \\
\hline $\begin{array}{l}\text { H-Double glazing: coated - } \\
\text { 6mm clear }\end{array}$ & $4.341 \mathrm{E}+00$ & $-1.280 \mathrm{E}+01$ & $1.478 \mathrm{E}+01$ & $-8.203 \mathrm{E}+00$ & $2.879 \mathrm{E}+00$ \\
\hline $\begin{array}{l}\text { I-Double Glazing:6mm tinted - } \\
\text { 6mm clear }\end{array}$ & $4.136 \mathrm{E}+01$ & $-1.178 \mathrm{E}+02$ & $1.276 \mathrm{E}+02$ & $-6.437 \mathrm{E}+01$ & $1.426 \mathrm{E}+01$ \\
\hline $\begin{array}{l}\text { J-Triple-Coated-3mm clear- } \\
\text { coated }\end{array}$ & $4.490 \mathrm{E}+00$ & $-1.266 \mathrm{E}+01$ & $1.397 \mathrm{E}+01$ & $-7.501 \mathrm{E}+00$ & $2.693 \mathrm{E}+00$ \\
\hline
\end{tabular}

\section{Step 8: Hemispherical Properties}

$\mathrm{E}+$ has a procedure for integrating the transmittance at angles of incidence from 0 to 90 to determine the hemispherical or diffuse transmittance. This is the same procedure as used 
in WINDOW and is a simple integral. See section 7.3 of Finlayson 1993 for more information.

\section{Conclusions and Future Work}

This paper presents a methodology developed for the Energy Plus simulation program so that it can use the common window indices U and SHGC (and optionally VT) to model energy impacts of windows in whole buildings. Previously, users had to model the details of the window construction - a method which should still be used when such detailed construction specifics are known. However for many studies of building energy performance, this generic method can be more versatile.

This method has been incorporated into Energy Plus version 4.00, released in October 2009. As this feature is used, it is reasonable to expect that small improvements to the procedure will be developed.

While this procedure was developed specifically for Energy Plus, parts of all of the procedures developed here may be useful to other building simulation applications.

\section{Acknowledgements}

This work was supported by the Assistant Secretary for Energy Efficiency and Renewable Energy, Building Technologies Program, of the U.S. Department of Energy under Contract No. DE-AC02-05CH11231.

\section{References}

ISO 15099, 2003. Thermal Performance of Windows, Doors and Shading Devices Detailed Calculations.

Finlayson, E. et. al. WINDOW 4.0 Documentation of Calculation Procedures.

Lawrence Berkeley National Laboratory report, LBL-33943. July 1993.

http://gaia.lbl.gov/btech/papers/33943.pdf 


\section{Appendix 1: Ts and SHGC: Turning center-of-glass relationships into whole window relationships}

The data presented in Figure 3 shows a relationship between Ts and SHGC for center-ofglass properties. As the following analysis shows, this same relationship holds for whole window Ts vs. SHGC.

Our technical procedure is based on starting with the SHGC of the window and wanting to end up with the Solar Transmittance of the window.

\section{$\mathrm{S}=\mathrm{SHGC}$}

$\mathrm{T}=$ Solar Transmittance

w refers to window; $g$ to glass area; $f$ to frame

Fg is fraction glass area

$\mathrm{Ff}$ is fraction frame area

$\mathrm{Sw}=\mathrm{FgSg}+\mathrm{FfSf}$

(SHGC of window is area weighted glass and frame SHGC's)

We need to assume FfSf is zero. This is a reasonable assumption since the only windows where there is any appreciable frame absorptance are aluminum frames which will have small fractional areas.

Thus

$\mathrm{Sw}=\mathrm{FgSg} \quad$ or $\mathrm{Sg}=\mathrm{Sw} / \mathrm{Fg}$

Figures $4 \mathrm{a}$ and $4 \mathrm{~b}$ show that $\mathrm{Tg}$ is a function of SHGCg:

$\mathrm{Tg}=\mathrm{KSg}$

Where $\mathrm{K}$ is the slope of the curve.

Also, since there is no solar transmittance through the frame

$\mathrm{Tw}=\mathrm{FgTg}$

Then, substituting:

$\mathrm{Tw}=\mathrm{FgKSg}$

$\mathrm{Tw}=\mathrm{FgKSw} / \mathrm{Fg}$

$\mathrm{Tw}=\mathrm{KSw}$ 


\section{Appendix 2: Estimating the Angular Properties of Windows knowing only their total $\mathrm{U}$ and SHGC}

\section{Background:}

As background material, we present a summary of the angular properties of individual glass layers, and then systems of layers. Glass transmittance is highest at normal incidence, decreasing to 0 when incident radiation is parallel to the plane of the glass. Angles of incidence are defined as angles from normal. Reflectances are lowest at normal incidence (0 degrees) and are $1.0(100 \%)$ at 90 degrees. Transmittance and reflectance curves for $3 \mathrm{~mm}$ clear glass are given in Figure A1. [Note: the data presented here are for solar transmittances and reflectances.]

As glass thickens or is tinted, it becomes more absorbing at angles away from normal. When this happens, the relative transmittance as a function of angle of incidence goes down, as shown in Figure A2, which shows normalized solar transmittance for clear and bronze, $3 \mathrm{~mm}$ and $6 \mathrm{~mm}$ glass.

Going from one to multiple glazing layers in a window also has an impact on angular properties. At angles away from normal, the reflectance increases significantly, thereby (relatively) reducing total transmittance. This is shown in Figure A3, which shows the normalized angular transmittance for single, double, and triple glazings of $3 \mathrm{~mm}$ clear glass.

It is important to understand that the angular properties of coated glass (either reflective coatings or low-e coatings) are not well understood, rarely measured, and hard to predict. This is due to the wide variety of materials used in coated layers, the involved composition of each coating layer, production variations, etc. For these reasons, the angular properties of all coated glazings have been approximated in the WINDOW and Energy Plus programs' detailed calculation procedures. Because of this, the layer-bylayer model for windows in EnergyPlus actually has a relatively basic model for angular performance. Two approximations are given for all coated glazings, one for layers with Ts $>.645$ and one for layers with Ts<.645, irregardless of the thickness or tint of the substrate glass. The correlations for coating with Ts $>.645$ are the same as those for $3 \mathrm{~mm}$ clear glass and for $\mathrm{Ts}<.645$, the same as for $3 \mathrm{~mm}$ bronze.

Figures A4 and A5 shows the normalized transmittances of clear vs. tinted glazings for $3 \mathrm{~mm}$ and $6 \mathrm{~mm}$ products. Note that clear products perform significantly differently than the tinted ones, which are relatively close in performance. Bronze and green, the two more common tinted products, are quite close. As will be discussed later on, we can use SHGC's to guess as to whether a product is likely to be tinted - but in such cases, we cannot guess what color it is tinted; in such cases we will thus use bronze to represent the performance of tinted products in general. 


\section{Angular Property Correlations}

Determining the angular properties of a window system knowing only its U and SHGC is an approximate exercise given all the impacts which are lumped into these total window properties. We can make some intelligent guesses as to the number of glazing layers and glazing type which will most often be true; such as low- U-factor windows most likely are triple glazed, very low SHGC windows are coated, etc. However, there are some effects we just cannot include, such as the fraction of total window which is frame and whether it has dividers (grids or divided lites). For example, large frame profiles and the use of dividers (such as what might be found in a "historical" wooden window) can take clear glass and give it the same total window SHGC as tinted glass in a typical aluminum framed window.

The table below has been developed with an understanding of the broader window market and window properties of various common window products. It aims to get the angular properties within reason, most of the time, knowing only $U$ and SHGC. A more accurate understanding of a window's angular properties would require additional information on the specific construction of the window. We identify whether specific segments of a 3x3 U-SHGC matrix are likely to be primarily Residential (3mm glass) or Commercial (6mm glass) products, how many layers they are likely to be made up of, and whether they are likely to be tinted or coated. In some cases, there is one likely configuration for a U-SHGC combination and for this "box," the angular properties of that glazing system are assigned. In other cases, there are multiple equally likely possibilities and in these cases the angular properties are averaged. 
Table A1:

\begin{tabular}{|c|c|c|c|}
\hline $\begin{array}{l}\text { Total Window } \\
\text { Properties }\end{array}$ & High U (U>4.5) & Mid-U $(1.7<U<3.4)$ & Low- U $(\mathrm{U}<1.4)$ \\
\hline $\begin{array}{l}\text { SHGC>.65 for } \\
\text { High U; } \\
\text { SHGC>.55 for } \\
\text { Mid U; } \\
\text { SHGC>.45 for } \\
\text { Low U; }\end{array}$ & $\begin{array}{l}\text { Single Glazing } \\
\text { Clear. Primarily } \\
\text { residential. } \\
3 \text { mm clear. } \\
\text { Commercial } \\
\text { products will be } \\
\text { few - angular } \\
\text { effects will be } \\
\text { similar. } \\
\text { (Angular Curve A.) }\end{array}$ & $\begin{array}{l}\text { Double glazed clear or } \\
\text { double low-e with a high } \\
\text { Ts low-e. Primarily } \\
\text { residential. } \\
3 \mathrm{~mm} \text { clear - } 3 \mathrm{~mm} \text { clear. } \\
3 \mathrm{~mm} \text { high Ts coated - } \\
3 \mathrm{~mm} \text { clear } \\
\text { (Angular Curve E) }\end{array}$ & $\begin{array}{l}\text { Unlikely } \\
\text { products; only } \\
\text { possibility is two } \\
\text { layer vacuum } \\
\text { glazings. } \\
\text { 3mm coated - } \\
\text { 3mm coated. } \\
\text { (Angular Curve E } \\
\text { applies here) }\end{array}$ \\
\hline $\begin{array}{l}.6<\text { SHGC }<.45 \\
\text { for High U } \\
.5<\text { SHGC<.3 } \\
\text { For Mid U } \\
.35<\text { SHGC }<.18 \\
\text { For Low U }\end{array}$ & $\begin{array}{l}\text { Single Glazing. } \\
\text { Could be } \\
\text { Residential tinted } \\
\text { (Curve B) or coated } \\
\text { (Curve D), } \\
\text { Commercial tinted } \\
\text { (Curve C) or coated } \\
\text { (Curve D). } \\
\text { (Angular curve } \\
\text { "BDCD" is an } \\
\text { average of these } \\
\text { four.) }\end{array}$ & $\begin{array}{l}\text { Double Glazing. } \\
\text { Outer layer could be } \\
\text { tinted or coated; inner } \\
\text { layer is clear. } \\
\text { Coated layer could be } \\
\text { low-e or reflective. } \\
\text { Could be Residential or } \\
\text { Commercial. } \\
\text { (Angular Curve "FGHI" } \\
\text { - average of F, G, H and } \\
\text { I) }\end{array}$ & $\begin{array}{l}\text { Triple glazing; } \\
\text { two layers are } \\
\text { coated and one is } \\
\text { clear. Primarily } \\
\text { Residential. } \\
\text { Commercial } \\
\text { products will be } \\
\text { few - angular } \\
\text { effects will be } \\
\text { similar } \\
3 \text { mm coated - } \\
3 \text { mm clear - 3mm } \\
\text { coated } \\
\text { (Angular Curve } \\
\text { J.) }\end{array}$ \\
\hline $\begin{array}{l}\text { SHGC }<.3 \text { for } \\
\text { High U } \\
\text { SHGC }<.25 \text { for } \\
\text { Mid U } \\
\text { SHGC }<.15 \text { for } \\
\text { Low U }\end{array}$ & $\begin{array}{l}\text { Single Glazing. } \\
\text { Could be } \\
\text { Residential or } \\
\text { Commercial, coated } \\
\text { (reflective). } \\
\text { (Angular Curve D.) }\end{array}$ & $\begin{array}{l}\text { Double Glazing. } \\
\text { Outer layer is coated; } \\
\text { inner layer is clear. } \\
\text { Coated layer could be } \\
\text { low-e or reflective. } \\
\text { Could be Residential or } \\
\text { Commercial. } \\
\text { (Angular Curve "FH"- } \\
\text { average of F and H) }\end{array}$ & (Same as above.) \\
\hline
\end{tabular}

Angular Property Curves:

A. Single Glazing: $3 \mathrm{~mm}$ clear

B. Single Glazing: $3 \mathrm{~mm}$ bronze

C. Single Glazing: $6 \mathrm{~mm}$ bronze 
D. Single Glazing Coated (any thickness, any coating)

E. Double Glazing: $3 \mathrm{~mm}$ clear $-3 \mathrm{~mm}$ clear (same relationship if glass has a high Ts coating)

F. Double Glazing: coated $-3 \mathrm{~mm}$ clear

G. Double Glazing: $3 \mathrm{~mm}$ tinted $-3 \mathrm{~mm}$ clear

H. Double Glazing: coated $-6 \mathrm{~mm}$ clear

I. Double Glazing: $6 \mathrm{~mm}$ tinted $-6 \mathrm{~mm}$ clear

J. coated $-3 \mathrm{~mm}$ clear - coated

The curves presented below are normalization factors applied to the transmittance and reflectance at normal ( 0 degrees) incidence. Thus, for transmittance, the normalization factor is 1.0 at normal incidence and 0 at 90 degrees. For reflectance, the normalization factor is 1.0 at normal incidence (where reflectance is between .05 and .1 typically), increasing to something on the order of 10-20 at 90 degrees (where the reflectance is 1.0). As noted in the beginning, all the angular correlations presented here were developed based on generic product solar transmission and reflection data. We use these same correlations for the angular correlations for visible transmittance and reflectance due to the fact that they are inherently similar. When implementing these correlations, we propose that:

- the normalized transmittances be forced to 1.0 and 0 at 0 degrees and 90 degrees respectively;

- the normalized reflectance be forced to 1.0 at 0 degrees and the absolute reflectance be forced to 1.0 at 90 degrees;

- these curves be used to generate data between 10 and 80 degrees; with linear interpolation between 0 and 10 degrees, and then between 80 and 90 degrees.

$\mathrm{Z}=\cos$ (angle)

$T$ or $R=a^{\star} Z^{\wedge} 4+b^{\star} Z^{\wedge} 3+c^{\star} Z^{\wedge} 2+d^{\star} Z+e$

\begin{tabular}{|l|r|r|l|l|l|}
\hline & \multicolumn{5}{|c|}{ Normalized Transmittance } \\
\hline & $\mathrm{a}$ & $\mathrm{b}$ & $\mathrm{l}$ & $\mathrm{d}$ & $\mathrm{e}$ \\
\hline & & & & - & \\
A-3 $\mathrm{mm}$ clear & $1.470 \mathrm{E}-02$ & $1.486 \mathrm{E}+00$ & $3.852 \mathrm{E}+00$ & $3.355 \mathrm{E}+00$ & $-1.474 \mathrm{E}-03$ \\
\hline B-3 mm bronze & $5.546 \mathrm{E}-01$ & $3.563 \mathrm{E}-02$ & $2.416 \mathrm{E}+00$ & $2.831 \mathrm{E}+00$ & $-2.037 \mathrm{E}-03$ \\
\hline C- $6 \mathrm{~mm}$ bronze & $7.709 \mathrm{E}-01$ & $-6.383 \mathrm{E}-01$ & $1.576 \mathrm{E}+00$ & $2.448 \mathrm{E}+00$ & $-2.042 \mathrm{E}-03$ \\
\hline & & & & - & \\
D-Single Coated & $3.462 \mathrm{E}-01$ & $3.963 \mathrm{E}-01$ & $2.582 \mathrm{E}+00$ & $2.845 \mathrm{E}+00$ & $-2.804 \mathrm{E}-04$ \\
\hline E-Double clear 3 mm & $2.883 \mathrm{E}+00$ & $-5.873 \mathrm{E}+00$ & $2.489 \mathrm{E}+00$ & $1.510 \mathrm{E}+00$ & $-2.577 \mathrm{E}-03$ \\
\hline F-Double coated 3 mm clear & $3.025 \mathrm{E}+00$ & $-6.366 \mathrm{E}+00$ & $3.137 \mathrm{E}+00$ & $1.213 \mathrm{E}+00$ & $-1.367 \mathrm{E}-03$ \\
\hline G-Double 3mm tinted 3 mm & $3.229 \mathrm{E}+00$ & $-6.844 \mathrm{E}+00$ & $3.535 \mathrm{E}+00$ & $1.088 \mathrm{E}+00$ & $-2.891 \mathrm{E}-03$ \\
\hline
\end{tabular}




\begin{tabular}{|l|l|l|l|l|l|} 
clear & & & & \\
\hline $\begin{array}{l}\text { H-Double glazing: coated }-6 \\
\mathrm{~mm} \text { clear }\end{array}$ & $3.334 \mathrm{E}+00$ & $-7.131 \mathrm{E}+00$ & $3.829 \mathrm{E}+00$ & $9.766 \mathrm{E}-01$ & $-2.952 \mathrm{E}-03$ \\
\hline $\begin{array}{l}\text { I-Double Glazing:6mm tinted - } \\
6 \text { mm clear }\end{array}$ & $3.146 \mathrm{E}+00$ & $-6.855 \mathrm{E}+00$ & $3.931 \mathrm{E}+00$ & $7.860 \mathrm{E}-01$ & $-2.934 \mathrm{E}-03$ \\
\hline $\begin{array}{l}\text { J-Triple-Coated-3mm clear- } \\
\text { coated }\end{array}$ & $3.744 \mathrm{E}+00$ & $-8.836 \mathrm{E}+00$ & $6.018 \mathrm{E}+00$ & $8.407 \mathrm{E}-02$ & $4.825 \mathrm{E}-04$ \\
\hline
\end{tabular}

\begin{tabular}{|l|r|r|l|l|l|}
\hline & \multicolumn{5}{|c|}{ Normalized Reflectance } \\
\hline & $\mathrm{a}$ & $\mathrm{b}$ & $\mathrm{c}$ & $\mathrm{d}$ & $\mathrm{e}$ \\
\hline $\mathrm{A}-3 \mathrm{~mm}$ clear & $1.632 \mathrm{E}+01$ & $-5.782 \mathrm{E}+01$ & $7.924 \mathrm{E}+01$ & $-5.008 \mathrm{E}+01$ & $1.334 \mathrm{E}+01$ \\
\hline B- 3 mm bronze & $4.048 \mathrm{E}+01$ & $-1.193 \mathrm{E}+02$ & $1.348 \mathrm{E}+02$ & $-7.097 \mathrm{E}+01$ & $1.611 \mathrm{E}+01$ \\
\hline C- 6 mm bronze & $5.749 \mathrm{E}+01$ & $-1.645 \mathrm{E}+02$ & $1.780 \mathrm{E}+02$ & $-8.875 \mathrm{E}+01$ & $1.884 \mathrm{E}+01$ \\
\hline D-Single Coated & $5.714 \mathrm{E}+00$ & $-1.667 \mathrm{E}+01$ & $1.863 \mathrm{E}+01$ & $-9.756 \mathrm{E}+00$ & $3.074 \mathrm{E}+00$ \\
\hline E-Double clear 3 mm & $-5.488 \mathrm{E}-01$ & $-6.498 \mathrm{E}+00$ & $2.120 \mathrm{E}+01$ & $-2.097 \mathrm{E}+01$ & $7.814 \mathrm{E}+00$ \\
\hline $\begin{array}{l}\text { F-Double coated 3 mm clear } \\
\text { G-Double 3mm tinted 3 mm } \\
\text { clear }\end{array}$ & $4.290 \mathrm{E}+00$ & $-1.267 \mathrm{E}+01$ & $1.466 \mathrm{E}+01$ & $-8.153 \mathrm{E}+00$ & $2.871 \mathrm{E}+00$ \\
\hline $\begin{array}{l}\text { H-Double glazing: coated -6 } \\
\text { mm clear }\end{array}$ & $2.174 \mathrm{E}+01$ & $-6.444 \mathrm{E}+01$ & $7.489 \mathrm{E}+01$ & $-4.179 \mathrm{E}+01$ & $1.062 \mathrm{E}+01$ \\
\hline $\begin{array}{l}\text { I-Double Glazing:6mm tinted - } \\
\text { 6 mm clear }\end{array}$ & $4.341 \mathrm{E}+00$ & $-1.280 \mathrm{E}+01$ & $1.478 \mathrm{E}+01$ & $-8.203 \mathrm{E}+00$ & $2.879 \mathrm{E}+00$ \\
\hline $\begin{array}{l}\text { J-Triple-Coated-3 mm clear- } \\
\text { coated }\end{array}$ & $4.136 \mathrm{E}+01$ & $-1.178 \mathrm{E}+02$ & $1.276 \mathrm{E}+02$ & $-6.437 \mathrm{E}+01$ & $1.426 \mathrm{E}+01$ \\
\hline
\end{tabular}

Transmission and Reflection $3 \mathrm{~mm}$ Clear

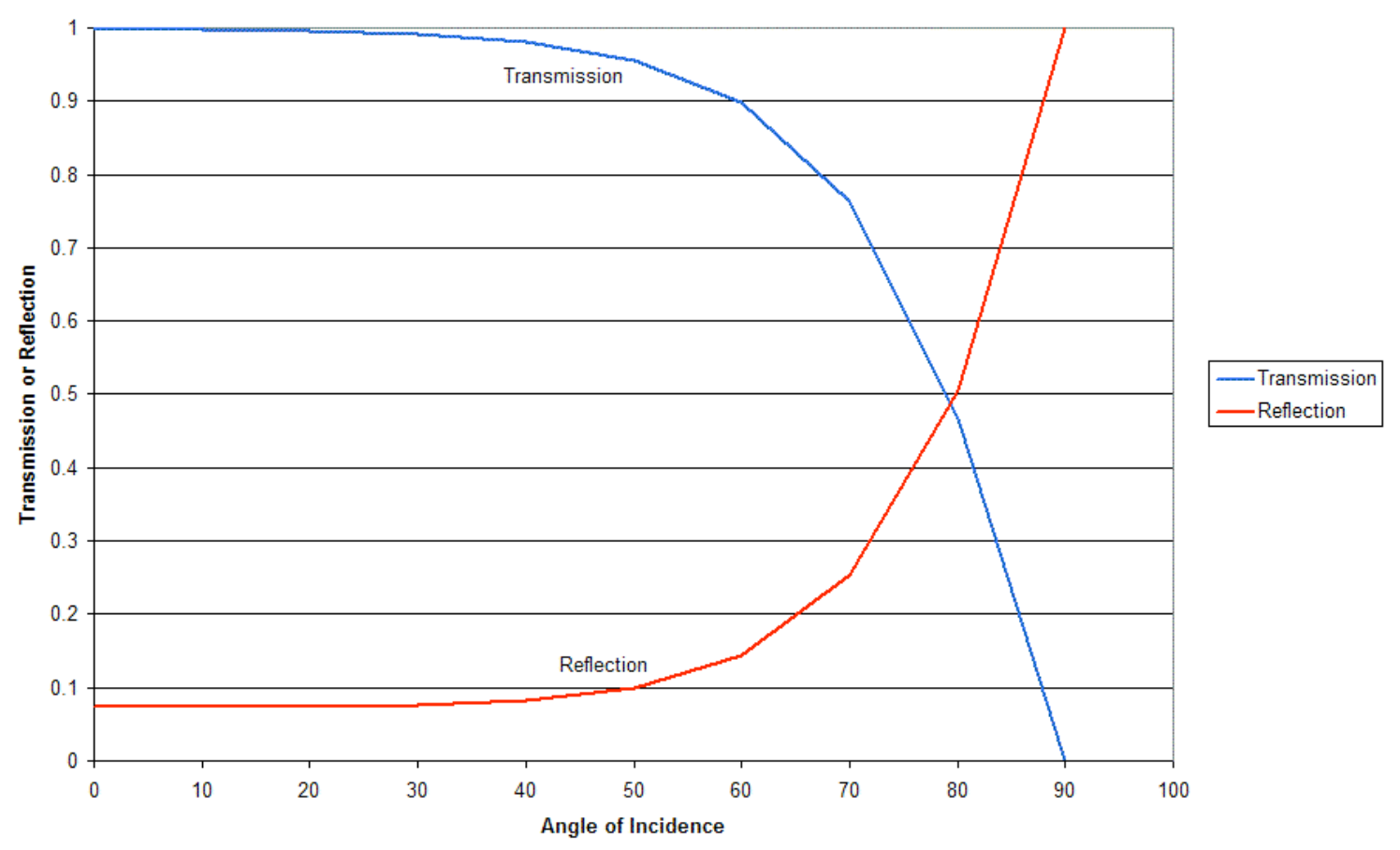

Figure A1 


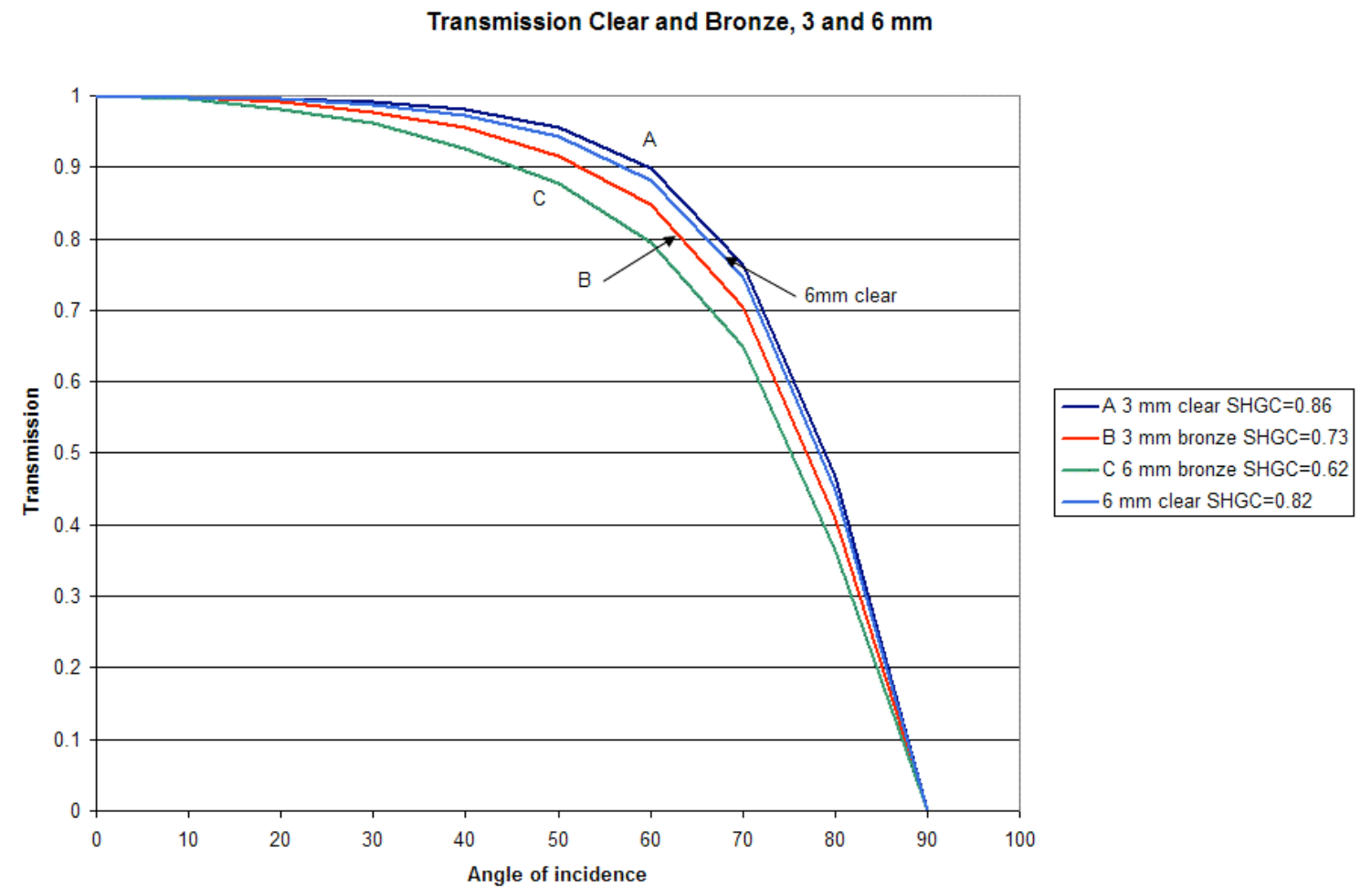

\section{Figure A2}

Transmission, Single, Double, Triple

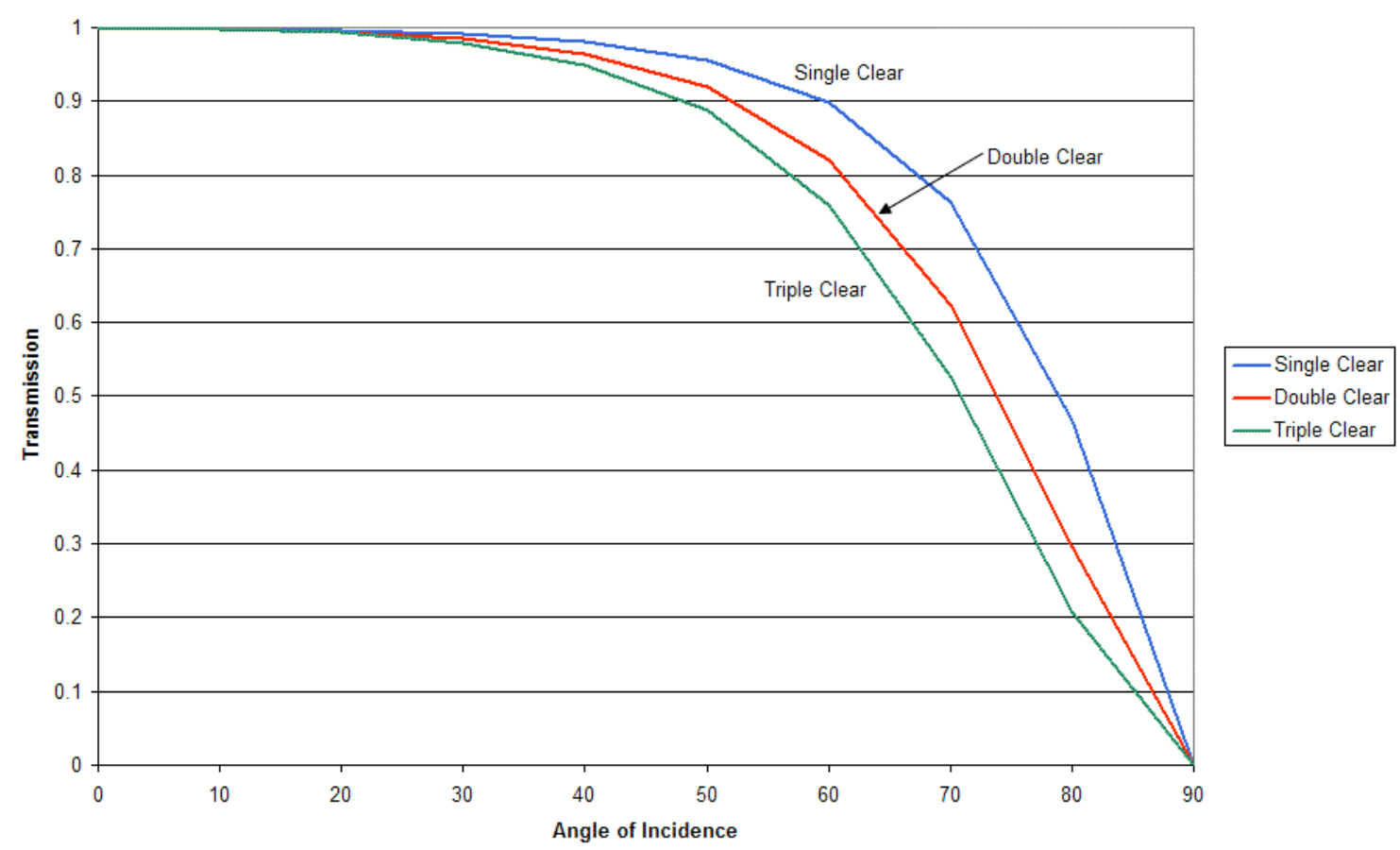

Figure A3 


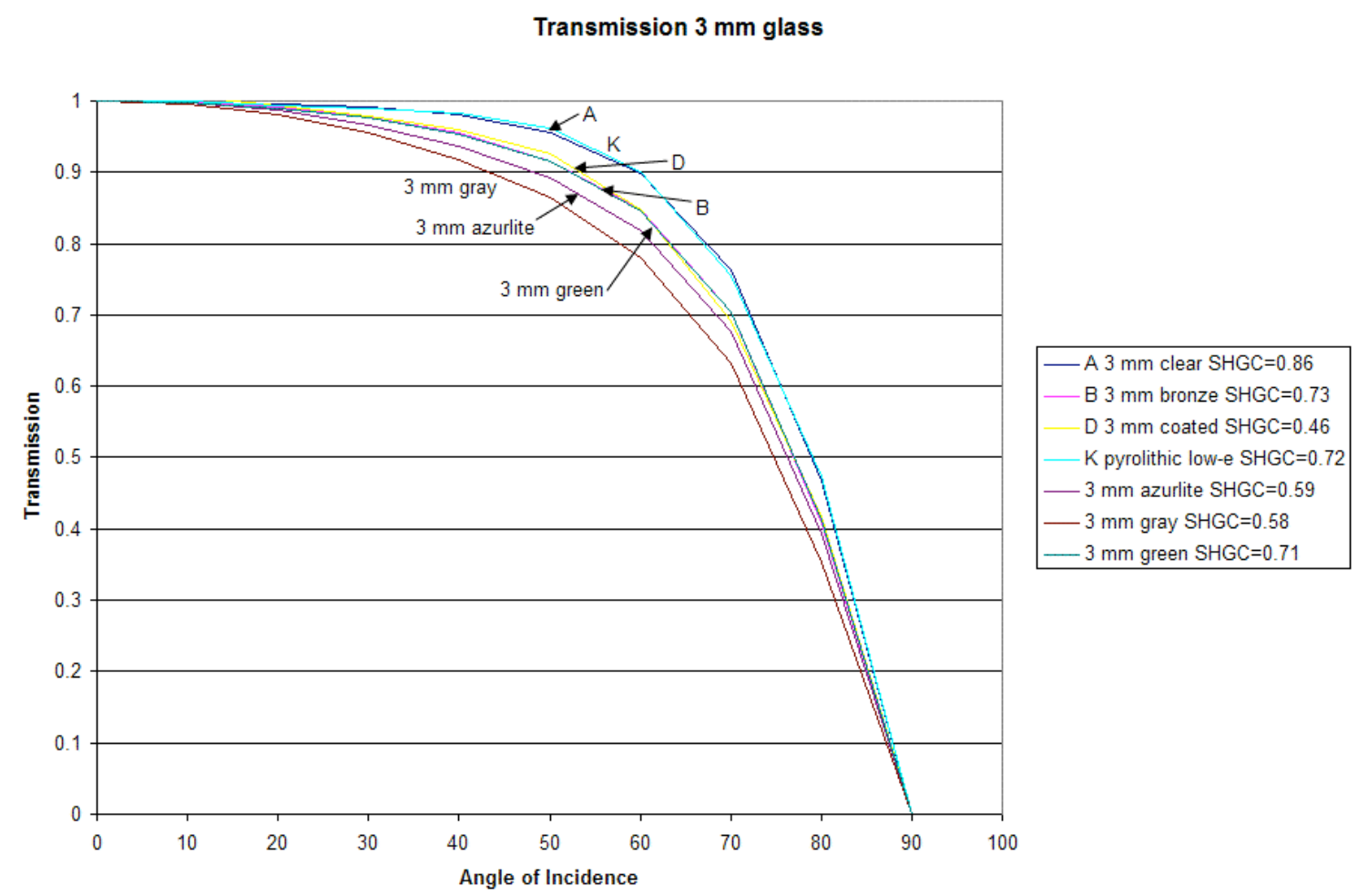

Figure A4

Transmission $6 \mathrm{~mm}$ glass

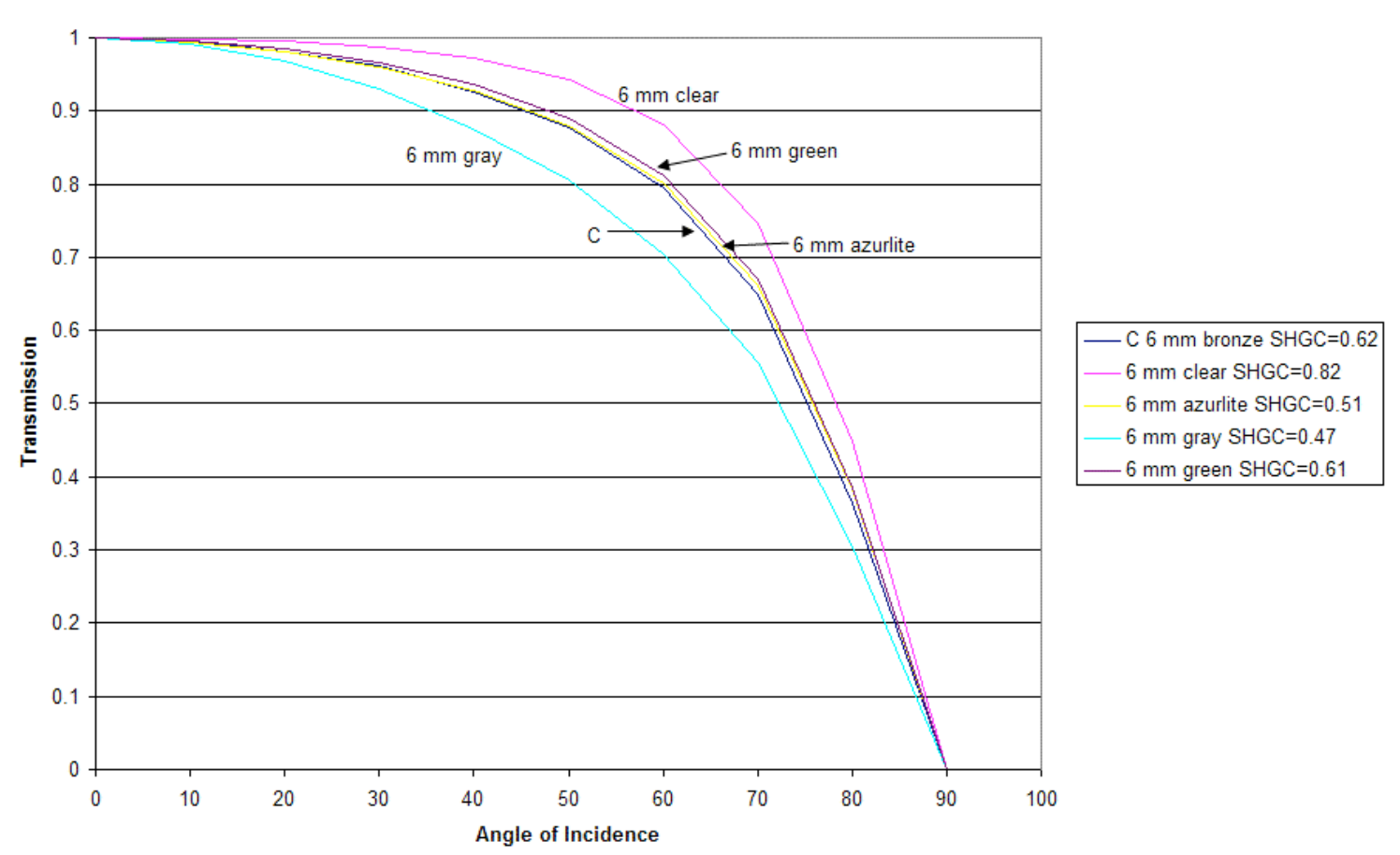

\section{Figure A5}


Notes on Determining the transition values for the $3 \times 3$ matrix:

This procedure relies on estimating the number of glazing layers and types of glazing based on U-factors and SHGC. These transition $U$ and SHGC values (i.e. the values which define where one cell in the $3 \times 3$ matrix in Table Al begins or ends) are based on total window $U$ and SHGC values given for representative windows in the 2005 ASHRAE Handbook of Fundamentals(Ch 29. Table 2; Ch. 31 Tables 4 and 13 and Figure 34) along with an understanding of the window market.

The most important distinction is using the U-factor to determine the number of glazing layers. SHGC is generally of little additional help in determining the number of layers as there is too much variety in SHGC for a given number of layers. ASHRAE shows us that most common single glazed products have whole window $U$-factors above 0.8 and most double glazed products are below 0.6. This distinction also allows us to have a transition zone from 0.6 to 0.8 ; transition zones where interpolation is used for angular properties are important in order to smooth out angular property effects when looking at energy use as a function of $U$ or SHGC. To determine the transition between double and triple glazing, we need to use more than just the data in these tables; it is important to know that triple glazing is costly to manufacture (low-e double glazing is much more versatile and a superior performer) and not typically used by the industry. Triple glazing's main application would be for highly insulating windows $(U<1.4)$ where two of the three layers are coated. Most double glazed windows have total window U-factors $>1.7$, so this creates a transition zone between double and triple glazed products.

Once we have estimated the number of layers based on $U$, we can then use the data in these tables on typical glazing products SHGC to come up with a reasonable estimate of what types of glazing are most likely to be used. Note that it is often instructive to look at the center-of-glass SHGC's (SHGCc) and then assume frames reduce these values by approximately 20\%. For example, we note the following:

- SHGCc for single clear is > .81

- SHGCc for double clear is $>.70$

- SHGC for tinted single is between 0.59 and 0.73

-SHGC for tinted double is between 0.39 and 0.62

The cutoffs for Clear single glazings are thus proposed to be total window SHGCs of 0.65 and 0.55 for clear double. Tinted products begin approximately 0.05 lower, defining a transition zone.

Single glazed low-e products are a very rare product offering and are ignored in this analysis. There are few single glazed tinted products (except for very thick glass) with SHGCc below 0.59. Single glazed reflective products begin with SHGCs of about 0.39; we thus define 0.3 as the total window SHGC which defines reflective glass and 0.45 as the bottom of the tinted range with 0.30-0.45 being a transition zone.

As Table 34 in Ch. 31 shows us, there is a lot of overlap for mid-range SHGC products between tinted, low-e, and reflective glass. However, this is not as large a problem as it 
may first seem since; as noted earlier, the same correlations are used for low-e and reflective glass (and that those are the correlations for $3 \mathrm{~mm}$ bronze). From table 13, we note that the lowest SHGCc for tinted double glazing is .39, implying that any double glazed window with a SHGC of .3 or below will be coated.

While some windows use laminated glass (and thicker glass than 6mm), this adds a dimension of complexity to the proposed system which would only diffuse the boundaries between the categories presented here. Generally, the use of laminated glass would reduce SHGC but not change our prediction of the number of layers. Laminated glass would push the SHGC boundaries for tinted glass lower. Given that the angular properties of tinted vs. coated glass are similar, this is not expected to introduce a large error. The main source of error would be confusing very thick or laminated clear glass with conventional tinted glass; but this overlap cannot be predicted. 


\section{Appendix 3: Example}

This example shows the values calculated for a window with a U-factor $=1.7 \mathrm{~W} / \mathrm{m} 2 \mathrm{~K}(0.3$ $\mathrm{Btu} / \mathrm{h}-\mathrm{ft} 2-\mathrm{F}), \mathrm{SHGC}=0.3$ and VT=0.4. All intermediate values in this example have been rounded, but for the calculation the full accuracy numbers were used.

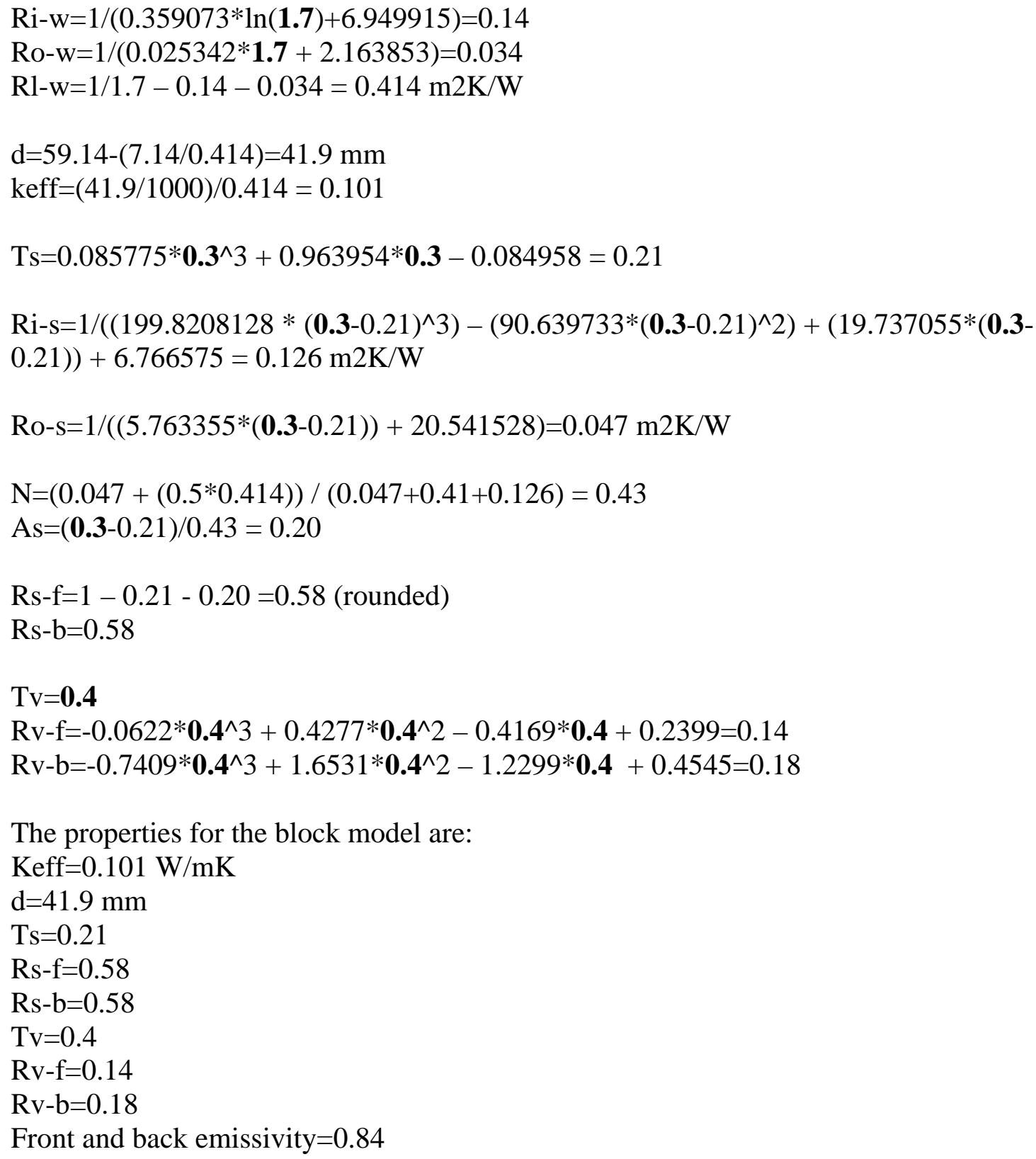

